Check for updates

Cite this: RSC Adv., 2019, 9, 4277

Received 29th November 2018 Accepted 18th January 2019

DOI: $10.1039 / c 8 r a 09833 f$

rsc.li/rsc-advances

\section{Synthesis, characterization and electrochemical analysis of cysteine modified polymers for corrosion inhibition of mild steel in aqueous $1 \mathrm{M}$ $\mathrm{HCl} \dagger$}

\begin{abstract}
Mohammad A. Jafar Mazumder (iD *
Butler's cyclopolymerization protocol was used to synthesize homo and copolymers of cysteine residues and diallyldimethylammonium chloride (DADMAC) using water as a solvent and excellent yields were obtained. The structural composition of the polymers was determined using nuclear magnetic resonance (NMR) and Fourier-transform infrared (FT-IR) spectroscopies. The thermal stability of the synthesized polymers was determined using thermogravimetric analysis (TGA). The corrosion efficiencies and adsorption characteristics of these polymers on mild steel were evaluated using gravimetric weight loss and potentiodynamic polarization, and electrochemical impedance spectroscopy (EIS). The copolymers of cysteine residues and DADMAC exhibited excellent inhibition efficiencies in arresting mild steel corrosion in $1 \mathrm{M}$ hydrochloric acid $(\mathrm{HCl})$ at $60{ }^{\circ} \mathrm{C}$. The best fitted Langmuir, Temkin and Freundlich adsorption isotherms suggested that the adsorption process occurs through chemisorption and physisorption. The surface morphology of mild steel in the presence or absence of polymers was determined using atomic force microscopy (AFM), scanning electron microscopy (SEM) and energy dispersive X-ray spectroscopy (EDX), and X-ray photoelectron spectroscopy (XPS). This systematic study might provide a way to design new inhibitor compounds that could be beneficial in the field of biomedical science as well as for anti-corrosion applications.
\end{abstract}

\section{Introduction}

Corrosion is a process that damages metal because of its chemical reaction with the environment. ${ }^{1-3}$ Approximately $25 \%$ to $30 \%$ of the total economic losses in the oil and gas industry are because of the failure of pipes and other plant systems resulting from metallic corrosion. ${ }^{4-6}$ Mild steel which has a low carbon (C) content (up to $0.3 \%$ ) has high mechanical properties, and is found to be readily available, cheap and used for many applications in the oil and gas industries. ${ }^{7}$ Despite its good properties and applications, mild steel is highly susceptible to corrosion. Typically, corrosive acid solutions are widely used in the oil and gas industry for the removal of corrosive dusts, scales, sludges and etching of metal alloys. ${ }^{\mathbf{8} 9}$

Corrosion inhibitors are extensively used in the oil and gas industries for the protection of mild steel from corrosion particularly in aggressive acid media. Numerous papers have reported the use of organic $\mathrm{c}^{\mathbf{1 0 - 1 2}}$ and inorganic compounds ${ }^{13-15}$ as corrosion inhibitors, and classified them according to their mode of action. Typically, organic and inorganic inhibitors

Chemistry Department, King Fahd University of Petroleum and Minerals, Dhahran 31261, Saudi Arabia; Web: http://faculty.kfupm.edu.sa/CHEM/jafar/.E-mail: jafar@ kfupm.edu.sa; Fax: +966-13-860-4277; Tel: +966-13-860-7836

$\dagger$ Electronic supplementary information (ESI) available. See DOI: 10.1039/c8ra09833f interfere with the anodic or cathodic reactions occurring on the metal surfaces to minimize or eliminate the corrosion process. ${ }^{\mathbf{1 6}}$ However, most of the organic and inorganic inhibitors were expensive, and posed a dangerous threat to health and the environment. ${ }^{17}$ This has steered researchers towards the invention of cheap, readily available, nontoxic, most effective and environment friendly corrosion inhibitors that impart maximum efficiency and least impact on nature and mankind. ${ }^{18-20}$

Amino acids, which are biogenic, naturally occurring molecules, have been used in pharmaceuticals and biological applications for many years. ${ }^{\mathbf{2 1 , 2 2}}$ There are many reports which have been published in which amino acids have been described as an effective corrosion inhibitor in different aggressive media. ${ }^{2324}$ Cysteine and methionine have been studied for their corrosion inhibition of mild steel in $1 \mathrm{~N}$ sulfuric acid $\left(\mathrm{H}_{2} \mathrm{SO}_{4}\right)$, and were found to be a mixed-type inhibitors. ${ }^{25}$ Alanine and glycine have also been studied for the prevention of mild steel corrosion in $0.1 \mathrm{M}$ hydrochloric acid $(\mathrm{HCl})$, and their effectivenesses were found to be $80.0 \%$ and $78.9 \%$, respectively, at $10 \mathrm{mM} \cdot{ }^{26}$ Amin et al. tested the corrosion inhibition efficiency of alanine, cysteine and $S$-methyl cysteine for iron in $1 \mathrm{M} \mathrm{HCl}$, and maximum inhibition efficiencies were reported to be $77.3 \%$, $86.0 \%$ and $94.2 \%$, respectively, at $5.0 \mathrm{mM} .{ }^{27}$ Cysteine which contains a mercapto group in its molecular structure was found 
to be the most effective compared to the other inhibitors. Barouni et al. ${ }^{28}$ studied the inhibitive effect of valine, glycine, arginine, lysine and cysteine. This study revealed that cysteine, because of its - $\mathrm{SH}$ functionality, provides better inhibition efficiency than the other amino acids tested. The influence of sulfur containing amino acids, particularly methionine, cysteine, and $\mathrm{N}$-acetyl cysteine, on the corrosion behavior of mild steel in a highly concentrated solution of phosphoric acid $\left(\mathrm{H}_{3} \mathrm{PO}_{4}\right)$ in the presence and absence of chloride, fluoride and ferric ions $\left(\mathrm{Cl}^{-}, \mathrm{F}^{-}\right.$and $\left.\mathrm{Fe}^{3+}\right)$ ions were investigated by Morad et al..$^{29}$ The inhibitive effect of cysteine on copper metal in $0.6 \mathrm{M}$ sodium chloride $(\mathrm{NaCl})$ and $1 \mathrm{M} \mathrm{HCl}$ was also investigated by Ismail. ${ }^{30}$ The synergistic inhibitive effect of cysteine and copper(II) $[\mathrm{Cu}(\mathrm{II})]$ ions on iron in $0.5 \mathrm{M} \mathrm{H}_{2} \mathrm{SO}_{4}$ was investigated by ElDeab. ${ }^{31}$ Saifi et al. ${ }^{32}$ investigated the inhibitive action of cysteine, which promotes the cathodic dissolution of a cupronickel $(\mathrm{Cu}-$ 30Ni) alloy in aerated $0.5 \mathrm{M} \mathrm{H}_{2} \mathrm{SO}_{4}$. Helal and Badawy ${ }^{33}$ studied the inhibitive action of some amino acids including phenylalanine and cysteine on magnesium-zinc-aluminium ( $\mathrm{Mg}-\mathrm{Zn}-$ Al) alloy in chloride free neutral solutions. The halide and cationic, anionic and non-ionic surfactants have also been added to the amino acid L-cysteine for the improvement of its inhibition efficiency, but no significant improvement of inhibition efficiency was observed..$^{34}$

In recent years, different polymers have been studied as potential corrosion inhibitors because of their availability, stability, processability, cost effectiveness, large surface area, and multiple anchoring sites in the form of atoms and/or functional groups which can easily form a bond with metal ions and adsorb onto the metal surface. ${ }^{35-37}$ Poly(vinylpyrrolidone) and polyethylenimine in $\mathrm{H}_{3} \mathrm{PO}_{4}$ have been used to study the corrosion efficiency of low carbon steel. ${ }^{38}$ Poly(diallydimethylammonium chloride) (pDADMAC) together with polyaniline has been successfully applied as a composite corrosion inhibitor for pure iron in $1 \mathrm{M} \mathrm{HCl}$. The maximum inhibition efficiency at a concentration of $150 \mathrm{ppm}$ was reported to be $59.0 \%$ for $25.0 \%$ pDADMAC containing a polyaniline composite. ${ }^{39}$ There are huge demands for pDADMAC, excluding its use in other applications, over 35 million pounds of it alone are sold per year for water purification and personal care formulations. ${ }^{40}$ In view of its performance, efficiency and applicability of pDADMAC and amino acids, it was realized that a polymer having diallylammonium salts with a cysteine residue would keep the integrity of its sulfide motifs, carboxyl groups and unquenched nitrogen $(\mathrm{N})$ valency (i.e., a trivalent $\mathrm{N}$ with its lone pair of electrons), which might be useful to protect mild steel from corrosion.

In this paper, the synthesis of homo and copolymers of pDADMAC and cysteine residues, and studies of the inhibitive actions of this new class of synthetic polymers as corrosion inhibitors for mild steel in $1 \mathrm{M} \mathrm{HCl}$ are reported. The presence of quaternized as well as $\mathrm{pH}$-responsive $\mathrm{N}$ together with oxygen (O) and sulfur (S) as well as multiple anchoring points in a polymer chain has provided an opportunity for the evaluation of their inhibition efficiencies as a potential green corrosion inhibitor in $1 \mathrm{M} \mathrm{HCl} \mathrm{using} \mathrm{different} \mathrm{spectroscopic,} \mathrm{microscopic}$ and electrochemical techniques.

\section{Experimental}

\subsection{Materials}

The diallyldimethylammonium chloride (DADMAC) and poly(diallyldimethylammonium chloride) (pDADMAC) (40 wt $\%$ solution in water) and 2,2'-azobis(2-methylpropionamidine) dihydrochloride (AMPD) initiator were purchased from SigmaAldrich and used as received. The $S$-methyl-t-cysteine 1 (Scheme 1) was obtained from Fluka Chemie $A G$ and used as received. Thionyl chloride $\left(\mathrm{SOCl}_{2}\right), \mathrm{HCl}(37 \% \mathrm{w} / \mathrm{v})$, methanol $\left(\mathrm{CH}_{3} \mathrm{OH}\right)$, acetone, diethyl ether, acetonitrile and potassium carbonate $\left(\mathrm{K}_{2} \mathrm{CO}_{3}\right)$ were purchased from BDH Chemical Ltd and used as received. Allyl bromide was obtained from Fluka Chemie AG and used without further purification. Water $\left(\mathrm{H}_{2} \mathrm{O}\right)$ was purified and de-ionized using a Milli-Q system from Millipore. All glassware was cleaned using de-ionized water. The detailed procedure for the synthesis of methyl-2-amino-3-methylthiopropanoate hydrochloride (2), $N, N$-diallyl-L-cysteine methyl ester (3), $N, N$-diallyl-L-cysteine methyl ester hydrochloride (4), and cysteine residual cationic monomer (6) (Scheme 1) are given in the ESI. $\dagger$

\subsection{Characterization}

A PerkinElmer 16F PC Fourier-transform-infrared (FT-IR) spectroscope was used to record the IR spectra, and proton nuclear magnetic resonance $\left({ }^{1} \mathrm{H}-\mathrm{NMR}\right)$ and carbon-13 NMR $\left({ }^{13} \mathrm{C}-\mathrm{NMR}\right)$ spectra were obtained using a Jeol LA $500 \mathrm{MHz}$ nuclear magnetic resonance (NMR) spectrometer. Elemental analysis was performed using a PerkinElmer 2400 elemental analyzer. An Ubbelohde viscometer with a viscometer constant of $0.005317 \mathrm{~mm}^{2} \mathrm{~s}^{-2}$ was used to determine the intrinsic viscosity of the synthesized polymers. A TA Instruments SDT Q600 thermogravimetric analyzer was used to perform the thermogravimetric analysis (TGA) under nitrogen $\left(\mathrm{N}_{2}\right.$; flow rate of 50 $\mathrm{mL} \min ^{-1}$ ) using a matched platinum/platinum-rhodium thermocouple pair, and increasing the temperature from 20 $800{ }^{\circ} \mathrm{C}$ by $10{ }^{\circ} \mathrm{C} \mathrm{min}^{-1}$.

\subsection{Test solutions}

The $\mathrm{HCl}$ solution was prepared by diluting the concentrated $\mathrm{HCl}(37 \%$, reagent grade) to a concentration of $1 \mathrm{M}$, with distilled, de-ionized water. The polymer compounds 7-9 at the required concentration in ppm were dissolved in $1 \mathrm{M} \mathrm{HCl}$. The $1 \mathrm{M} \mathrm{HCl}$ solution containing no polymer compound was used as the blank.

\subsection{Synthesis}

2.4.1 Synthesis of cysteine residue containing cationic homo polymer (7). The polymerization for the synthesis of the cysteine residue containing cationic homo polymer (7) was carried out following Butler's cyclopolymerization protocol ${ }^{41,42}$ under the conditions described in Table 1 . The monomer precursor 6 (2.01 g; $8.0 \mathrm{mmol})$, and AMPD (0.439 g, $1.62 \mathrm{mmol})$ initiator were dissolved in de-ionized water $(0.749 \mathrm{~g})$ and conc. $\mathrm{HCl}(37 \% ; 0.223 \mathrm{~g}, 24.3 \mathrm{mmol})$ in a $10 \mathrm{~mL}$ round bottomed flask. The solution was gently bubbled with $\mathrm{N}_{2}$ for $5 \mathrm{~min}$, then heated 
<smiles>CNCC(N)C(=O)O</smiles>

1

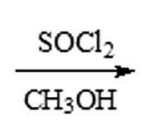<smiles>CCCC(CC)C(C)=O</smiles>

2<smiles>C=CCC(CC=C)C(CC(C)(C)C)C(=O)[O-]</smiles>

5<smiles></smiles>

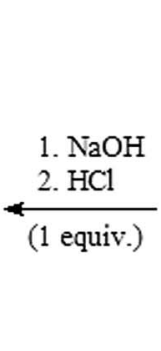<smiles>C=CCC(CC=C)N(CC=C)C(C)C(=O)OC</smiles>

4

Scheme 1 Synthesis of cysteine-based diallylamine salts - monomer.

in the flask at $90{ }^{\circ} \mathrm{C}$ for $40 \mathrm{~h}$. After $40 \mathrm{~h}$, the polymer was dissolved in de-ionized water $(4 \mathrm{~mL})$, dialyzed in presence of $\mathrm{HCl}$ $(0.1 \mathrm{M})$ and then freeze dried to give polymer (7). Yield: $1.64 \mathrm{~g}$, $81 \%$. Elemental analysis of $\mathrm{C}_{13} \mathrm{H}_{24} \mathrm{ClNO}_{2} \mathrm{~S}$ : calculated: $\mathrm{C}, 47.7$; H, 7.21; N, 5.56; S, 12.7; found: C, 46.9; H, 7.05; N, 5.72; S, 12.1. The thermal decomposition of the cysteine residue of polymer sulfide 7: $220-230{ }^{\circ} \mathrm{C}$ (decomposed, turned black).

2.4.2 Cyclocopolymerization of monomer 6 with DADMAC (8). The polymerization for the synthesis of the cationic cyclocopolymer of monomer 6 and DADMAC was carried out following a modified procedure described in an earlier report ${ }^{42}$ under the conditions described in Table 1 . Briefly, a mixture of monomer 6 ( $1.52 \mathrm{~g}, 6.0 \mathrm{mmol})$ and DADMAC (0.969 g, $6.0 \mathrm{mmol})$ in $1.06 \mathrm{~g} \mathrm{H}_{2} \mathrm{O}$ and $0.148 \mathrm{~g} \mathrm{HCl}(37 \%)$ were placed in a $10 \mathrm{~mL}$ round bottomed flask, and then polymerized using AMPD $(0.326 \mathrm{~g}, 1.20 \mathrm{mmol})$ initiator at $90{ }^{\circ} \mathrm{C}$ for $28 \mathrm{~h}$. The resultant crude polymer product was dialyzed (using MWCO 3-6 kDa dialysis tubing) against deionized water for $6 \mathrm{~h}$ followed by $2 \mathrm{~h}$ in $0.1 \mathrm{M} \mathrm{HCl}$, and then freeze dried. The isolated copolymer (8) was obtained as a white powder. Yield: $1.60 \mathrm{~g}, 65 \%$. The thermal decomposition of the copolymer of the cysteine residue of the polymer sulfide and DADMAC 8 was found to be $250-260{ }^{\circ} \mathrm{C}$ (decomposed, turned black).

\subsection{Mild steel sample}

The mild steel coupons (C1010, S\&A, WGH) were cut into a rectangular shape with a diameter of $2.5 \mathrm{~cm} \times 2.0 \mathrm{~cm}$ and a thickness of $0.1 \mathrm{~cm}$, and then used in the gravimetric weight loss measurements and surface analysis. The mild steel coupons having an approximate stem of $3 \mathrm{~cm}$ embedded in Araldite with a thickness of $1 \mathrm{~mm}$ and exposed area of $2 \mathrm{~cm}^{2}$ were used in all the electrochemical and impedance measurements. The mild steel samples were mechanically ground with different grades of emery paper (100, 400, 600 and 1500 grit size), followed by degreasing and cleaning with acetone. They were then washed with deionized water, dried in a vacuum oven and stored in a desiccator for further experiments. The percentage chemical compositions of the mild steel samples were as follows: $\mathrm{C}$ (0.089), $\mathrm{Cr}$ (0.037), $\mathrm{Cu}$ (0.005), $\mathrm{Fe}$ (99.47), $\mathrm{Mn}$ (0.34), Mo (0.007), Ni (0.022), P (0.010) and V (0.005).

\subsection{Corrosion evaluation methods}

2.6.1 Gravimetric weight loss method. Gravimetric weight loss measurements were carried out in triplicate using the preweighed mild steel coupons, described in Section 2.5, were immersed in $250 \mathrm{~mL}$ of $1 \mathrm{M} \mathrm{HCl}$ solution in the presence or

Table 1 Cyclopolymerization conditions ${ }^{a}$ and compositions

\begin{tabular}{|c|c|c|c|c|c|c|c|}
\hline Entry no. & Monomer (6) (mmol) & DADMAC (mmol) & $\begin{array}{l}\text { Solvent }(\mathrm{g}) \\
\text { (water/conc. } \mathrm{HCl} \text { ) }\end{array}$ & AMPD (mmol) & Time (h) & $\begin{array}{l}\text { Polymer } \\
\text { yield (\%) }\end{array}$ & {$[\eta]^{b}\left(\mathrm{dL} \mathrm{g}^{-1}\right)$} \\
\hline 1 & 8 & - & $(0.75 / 0.23)$ & 11.62 & 40 & (7) 81 & 0.153 \\
\hline 3 & - & - & - & - & & $(9)^{c}-$ & 0.174 \\
\hline
\end{tabular}

${ }^{a}$ Polymerization reactions were carried out using appropriate concentrations of monomer 6 with/without DADMAC in the presence of 2,2'-azobis(2methylpropionamidine)dihydrochloride (AMPD) initiator at $60{ }^{\circ} \mathrm{C}$ to give polymer 7 and 8 in solvent water/conc. HCl. ${ }^{b}$ Viscosity of $1-0.125 \%$ solution of 7, 8 and 9 in $0.1 \mathrm{M} \mathrm{NaCl}$ at $30.0 \pm 0.1{ }^{\circ} \mathrm{C}$ was measured using a Ubbelohde viscometer $\left(K=0.005317 \mathrm{~mm}^{2} \mathrm{~s}^{-2}\right)$.

${ }^{c}$ Poly(diallyldimethylammonium chloride) (pDADMAC) was obtained from Sigma-Aldrich. 


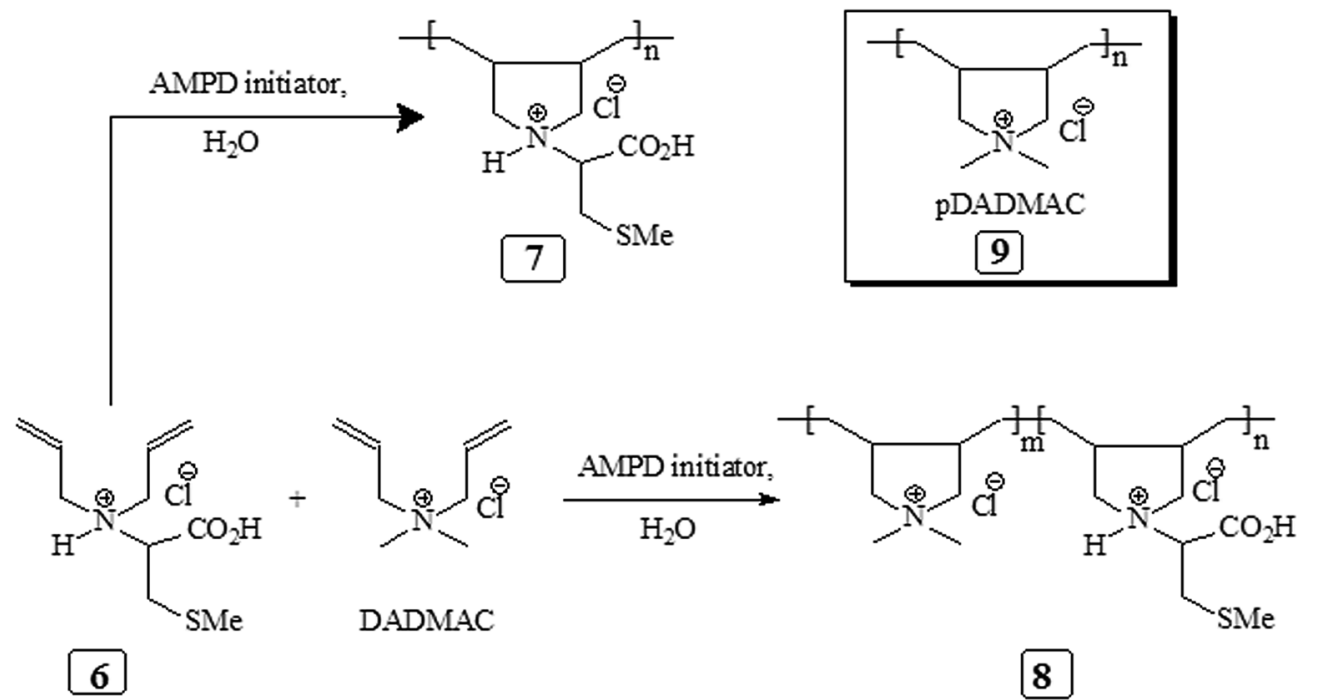

Scheme 2 Synthesis of cysteine-based diallylamine salts - DADMAC homo and copolymers.

absence of the synthesized polymers for $6 \mathrm{~h}$ at $60{ }^{\circ} \mathrm{C}$. After immersion, the mild steel coupons were removed from the solution, washed with de-ionized water, dried and re-weighed in order to determine the weight loss. The inhibition efficiency $(\eta \%)$ can be calculated from weight loss measurements using eqn (1):

$$
\eta \%=\frac{W_{\mathrm{b}}-W_{\mathrm{i}}}{W_{\mathrm{b}}} \times 100
$$

where $W_{\mathrm{i}}$ and $W_{\mathrm{b}}$ are the weight loss of the mild steel coupon in the presence or absence of polymer $(7,8$ or 9$)$, respectively.

In a temperature controlled bath, the weight loss measurements including three blanks were carried out as a set of experiments. For an example, when the weight loss experiments were performed for various concentrations of polymer 7 , three mild steel coupons with initial masses 4.1376, 4.0121 and $3.9505 \mathrm{~g}$ with surface areas of $11.42,11.41$ and $10.90 \mathrm{~cm}^{2}$, respectively, were analyzed without the polymer (blank). The blank samples lost masses of $0.3482,0.3302$ and $0.3354 \mathrm{~g}$, respectively, after $6 \mathrm{~h}$ immersion in $1 \mathrm{M} \mathrm{HCl}$ at $60^{\circ} \mathrm{C}$. Using the formula:

$$
\text { corrosion rate }\left(\mathrm{CR}_{\text {corr }} ; \mathrm{mm} \text { per year }\right)=87.6 \mathrm{~W} /(\mathrm{DAT})
$$

where $W=$ weight loss (mg), $D=$ metal density $\left(\mathrm{g} \mathrm{cm}^{-3}\right.$, which was $7.87 \mathrm{~g}$ for iron), $A=$ area of the sample in $\mathrm{cm}^{2}$, and $T=$ exposure time of metal sample $(\mathrm{h})$. The calculated corrosion rate was found to be $55.8 \pm 1.5 \mathrm{~mm}$ per year. The same experiments were repeated with other blank samples on several other occasions gave a $\mathrm{CR}_{\text {corr }}$ within 1-3\%.

\subsubsection{Electrochemical methods}

2.6.2.1 OCP versus time. The required time to reach steady open circuit potential (OCP) at the surface of mild steel coupons immersed in different concentrations ( 1 or $50 \mathrm{ppm}$ ) of polymer compounds 7, 8 and 9 for different times ( 0 to $240 \mathrm{~min}$ ) in $1 \mathrm{M}$ $\mathrm{HCl}$ solution, were measured.
2.6.2.2 Tafel extrapolation. The electrochemical measurements were conducted in a four necked round bottomed flask connected with a three electrode electrochemical cell in which a saturated calomel electrode (SCE), graphite rod and mild steel samples were used as reference electrode, auxiliary electrode and working electrode, respectively. Prior to the measurements, the electrodes were corroded in $1 \mathrm{M} \mathrm{HCl}$ containing test solution for $45 \mathrm{~min}$ at $60^{\circ} \mathrm{C}$ to reach a stable OCP. An Autolab 10ABST707A potentiostat-galvanostat (Eco Chemie) connected with a computer having NOVA software (version 1.8) recorded the polarization curves with a set cut off current of $10 \mathrm{~mA}$ and a potential scan window of $\pm 250 \mathrm{mV} / \mathrm{SCE}$ around the corresponding OCP with a scan rate of $0.5 \mathrm{mV} \mathrm{s}^{-1}$.

The corrosion current densities obtained from the polarization curves were used in eqn (2) to calculate the percentage inhibition efficiency:

$$
\eta(\%)=\left(\frac{i_{\text {corr }}^{\text {Blank }}-i_{\text {corr }}^{\text {Inhibitor }}}{i_{\text {corr }}^{\text {Blank }}}\right) \times 100
$$

where $i_{\text {corr }}^{\text {Inhibitor }}$ and $i_{\text {corr }}^{\text {Blank }}$ is the corrosion current density in the presence and absence of polymer compounds, respectively.

2.6.2.3 Linear polarization resistance (LPR). The LPR data was recorded using the same electrochemical cell and the conditions described in Section 2.6.2.2 (Tafel extrapolation) with a potential scan range of $\pm 10 \mathrm{mV}$ around $E_{\text {corr }}$. The surface coverage $(\theta)$ values were calculated from eqn (3) using the polarization resistance obtained in presence $(R / \mathrm{p}$ Inibitor $)$ and absence $\left(R l_{\mathrm{p}}^{\text {Blank }}\right)$ of polymer compounds:

$$
\eta(\%)=\left(\frac{R_{\mathrm{p}}^{\prime \text { Inhibitor }}-R_{\mathrm{p}}^{\text {'Blank }}}{R_{\mathrm{p}}^{\text {Inhhibitor }}}\right) \times 100
$$

2.6.2.4 Electrochemical impedance spectroscopy (EIS). The electrochemical cell, consisting of three electrodes, which were connected to the computerized potentiostat-galvanostat system 

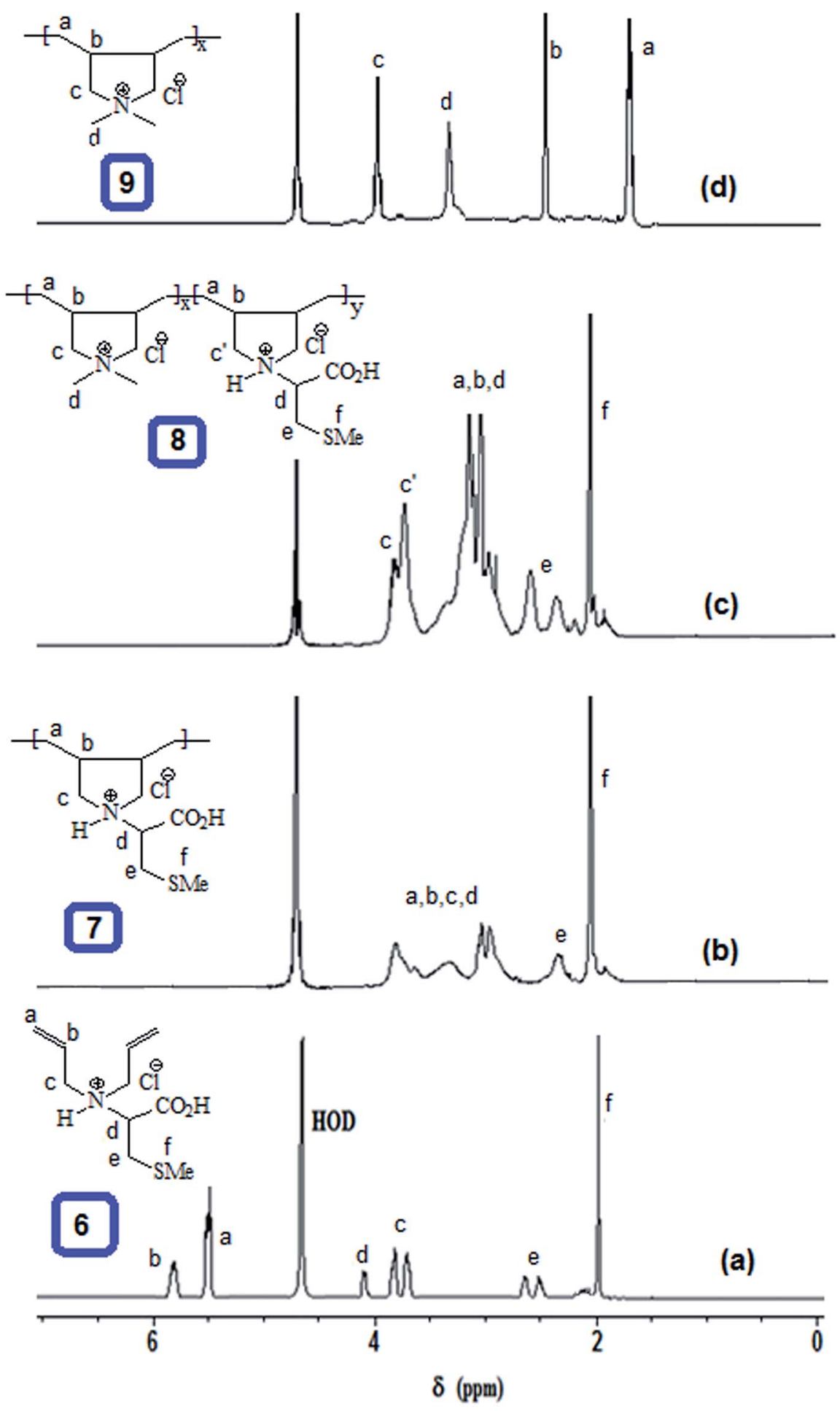

Fig. $1{ }^{1} \mathrm{H}$-NMR spectra of (a) 6, (b) 7, (c) 8 and (d) 9 in $\mathrm{D}_{2} \mathrm{O}$.

described in Section 2.6.2.2 (Tafel extrapolation), was used to measure the electrochemical impedance values in $1 \mathrm{M} \mathrm{HCl}$ containing test solution (presence or absence of polymers) at $60{ }^{\circ} \mathrm{C}$. The Nova software (version 1.8) was used to process the Nyquist and Bode plots at the corresponding OCP in a frequency range from $100 \mathrm{kHz}$ to $50 \mathrm{mHz}$ with an amplitude of $10 \mathrm{mV}$. The most suitable (lowest deviation from the experimental values) electrochemical equivalent circuit was used to fit the data obtained from impedance measurements.

\subsection{Surface characterization}

2.7.1 Atomic force microscopy (AFM). The surface morphologies of the mild steel in the presence or absence of 

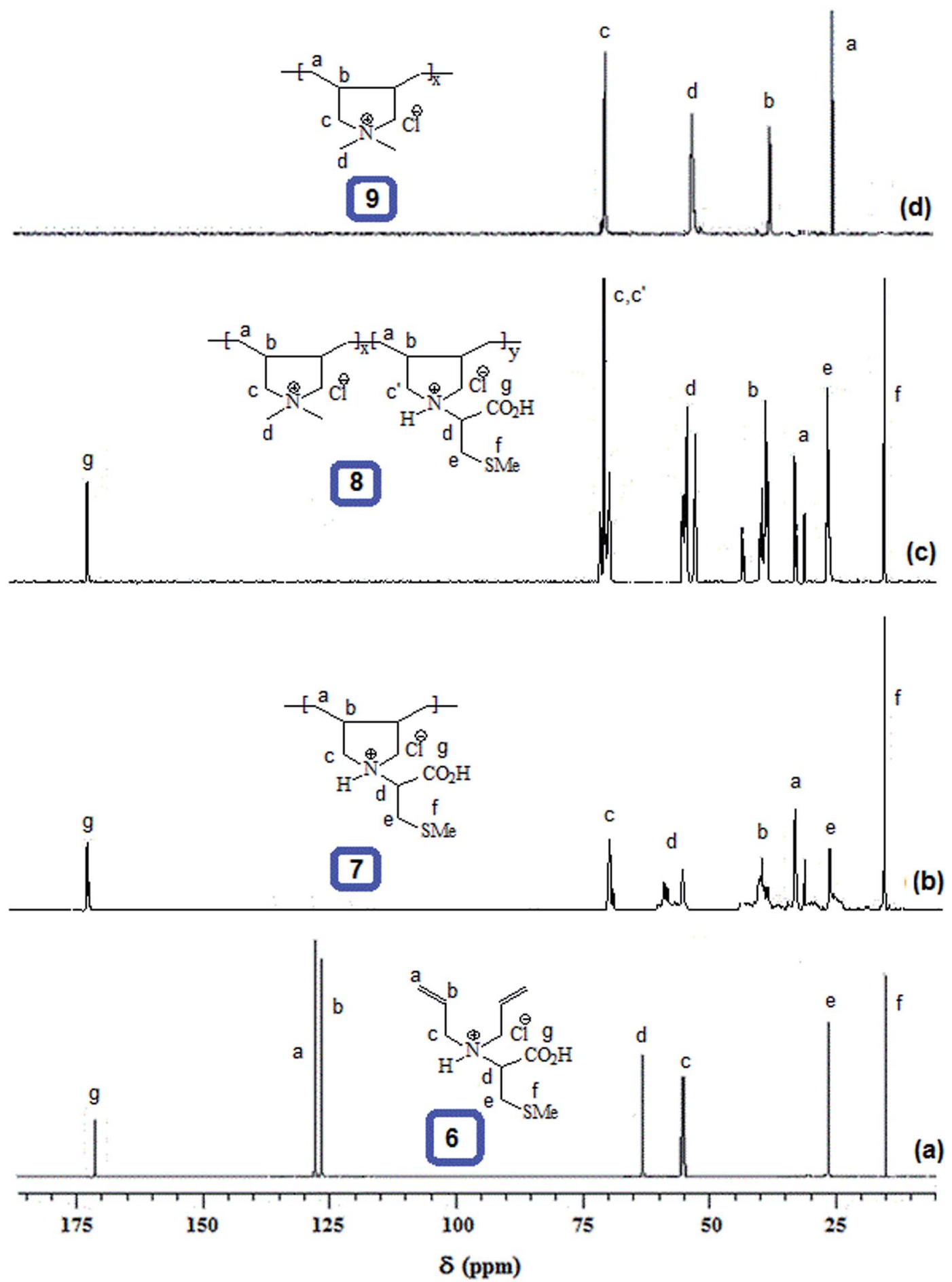

Fig. $2{ }^{13}$ C-NMR spectra of (a) 6, (b) 7, (c) 8 and (d) 9 in $\mathrm{D}_{2} \mathrm{O}$.

polymer compounds were studied using AFM. The rectangular shaped mild steel specimens (dimensions: $2.5 \mathrm{~cm} \times 2.0 \mathrm{~cm} \times$ $0.1 \mathrm{~cm}$ ) were immersed in the presence or absence of polymer 8 in $1 \mathrm{M} \mathrm{HCl}$ for $6 \mathrm{~h}$ at $60{ }^{\circ} \mathrm{C}$. After the immersion, the mild steel coupons were taken out from the test solution, washed with distilled, de-ionized water, dried, and stored in a desiccator. The mild steel coupon surfaces were analyzed using a NanoScope II atomic force microscope in tapping mode to capture the image. The surface data was processed using a powerful algorithm containing software.

2.7.2 X-ray photoelectron spectroscopy (XPS). The surface chemical compositions of the mild steel samples were studied using a Thermo Scientific Escalab 250Xi X-ray photoelectron spectrometer. The high resolution XPS spectra for Fe 2p, C 1s, O $1 \mathrm{~s}$ and $\mathrm{N}$ 1s were captured for bonding state analysis using Avantage software. The XPS spectra were deconvoluted using 


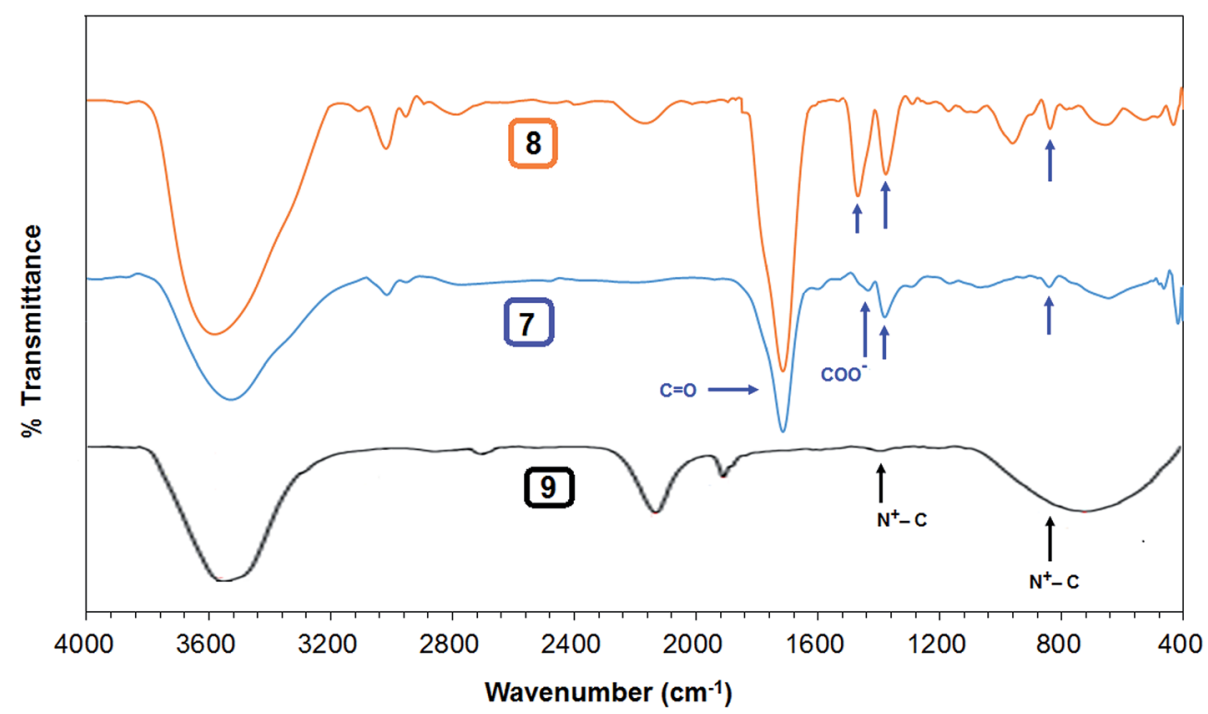

Fig. 3 FT-IR spectra of 7, 8 and 9

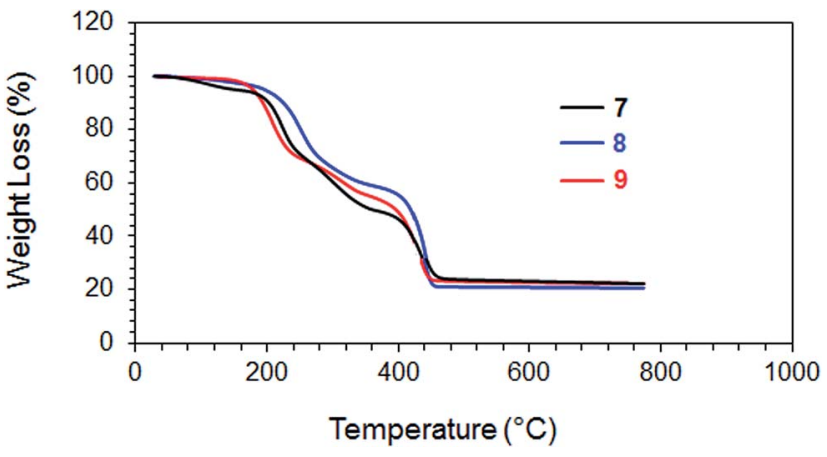

Fig. 4 TGA curves for the homo polymer 7 and 8 , and copolymer 9.

a non-linear least squares algorithm with a Shirley baseline and a Gaussian-Lorentzian combination. All the binding energies collected from XPS spectra were calibrated using a standard binding energy reference peak of C 1s $(285.4 \mathrm{eV})$.

2.7.3 SEM and EDX. The surface morphology of the mild steel samples that had been immersed in the presence or absence of polymer compound $8(100 \mathrm{ppm})$ in $1 \mathrm{M} \mathrm{HCl}$ for $6 \mathrm{~h}$ at $60{ }^{\circ} \mathrm{C}$, was studied using a Tescan (Brno - Kohoutovice, Czech

Table 2 The $\eta \%^{a}$ for inhibitors 7, 8 and 9 obtained using a gravimetric weight loss method for the inhibition of corrosion of mild steel at $60^{\circ} \mathrm{C}$ in $1 \mathrm{M} \mathrm{HCl}^{b}$ for $6 \mathrm{~h}$

\begin{tabular}{llllllll}
\hline & \multicolumn{7}{l}{$\eta(\%)$ at concentration of inhibitors (in ppm) } \\
\cline { 2 - 8 } Sample & 1.00 & 2.50 & 5.00 & 10.0 & 25.0 & 50.0 & 100 \\
\hline 7 & 43.4 & 51.2 & 60.3 & 71.4 & 82.3 & 85.1 & 87.6 \\
8 & 64.0 & 69.8 & 76.4 & 82.8 & 94.9 & 99.4 & 99.5 \\
9 & 31.9 & 45.2 & 54.0 & 65.4 & 77.1 & 81.7 & 82.3
\end{tabular}

${ }^{a}$ Inhibition efficiency, (i.e., $\left.\eta\right)=$ surface coverage $\theta .{ }^{b}$ Corrosion rate for a set of three blank experiments was found to be $55.8 \pm 1.5 \mathrm{~mm}$ per year. The blanks repeated on several other occasions gave a CR within 1-3\%.
Republic) Lyra3 field-emission scanning electron microscope (FESEM) with an electron beam at $25 \mathrm{kV}$. Furthermore, the chemical compositions and homogeneity mapping of the mild steel surface in the presence or absence of polymer was determined using an energy dispersive X-ray (EDX) spectroscope (Oxford Instruments, UK) fitted with an X-Max detector.

\section{Results and discussion}

\subsection{Synthesis of the polymer compounds}

The homo and copolymers of diallylammonium salts and/or their alternate copolymerization with DADMAC were synthesized in water using Butler's cyclopolymerization protocol ${ }^{\mathbf{4 0 , 4 3 - 4 5}}$ which is important in the syntheses of industrially significant ionic polymers 7 and 8 in excellent yields (Scheme 2). The pDADMAC is denoted as polymer 9. The structures of the monomers and polymers were characterized using NMR and FT-IR. The ${ }^{1} \mathrm{H}$-NMR and ${ }^{13} \mathrm{C}-\mathrm{NMR}$ spectra of 7, 8 and 9 are

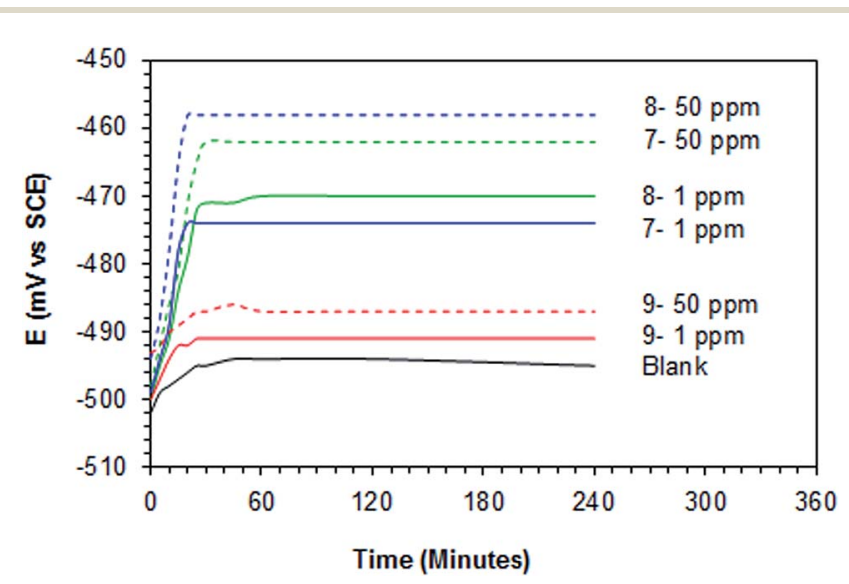

Fig. 5 Variation of the OCP of mild steel with time of immersion with different concentrations (1.0 and $50 \mathrm{ppm}$ ) of polymers 7-9 in $1 \mathrm{M} \mathrm{HCl}$ at $60^{\circ} \mathrm{C}$. 
shown in Fig. 1 and 2, respectively. The absence of alkene proton or carbon signals in the polymer spectra shows that the monomer has been converted to a polymer. A closer look at the proton spectrum of 7,8 and $\mathbf{9}$ in deuterium oxide $\left(\mathrm{D}_{2} \mathrm{O}\right)$ showed the presence of different $\mathrm{CH}_{2}$ signals at $3.68 \mathrm{ppm}$ and $3.80 \mathrm{ppm},{ }^{46-48}$ respectively, which were attributed to the presence of a polymer containing DADMAC and cysteine. The ${ }^{13} \mathrm{C}$ signals around $170 \mathrm{ppm}^{\mathbf{4 8}}$ were attributed to the carbonyl groups in the repeating units of 6, 7 and 8 (Fig. 2). However, no such signal appeared in the repeating unit of 9. The FT-IR spectra (Fig. 3) shows that a sharp stretching vibration around $3450 \mathrm{~cm}^{-1}$ which was attributed to the presence of a non/free hydrogen bonded $\mathrm{N}-\mathrm{H}$ group. ${ }^{47,48}$ Similarly, a strong absorption band appeared at $1705 \mathrm{~cm}^{-1}$ for 7 and 8 which was attributed to the presence of a non/free hydrogen bonded $\mathrm{C}=\mathrm{O}$ stretching vibration of the $\mathrm{CO}_{2} \mathrm{H}$ group. ${ }^{4,48}$ This stretching vibration band was absent in polymer 9. The symmetric and antisymmetric stretching band appeared at $\approx 1400$ and $\approx 1421 \mathrm{~cm}^{-1}$, respectively, and these were thought to be $\mathrm{COO}^{-}$ motifs in polymers 7 and $8 .^{49}$ The $\mathrm{C}-\mathrm{N}$ stretching and bending peak appeared at $\approx 1350$ and $\approx 800 \mathrm{~cm}^{-1}$, respectively, and were attributed to the $\mathrm{C}-\mathrm{N}-\mathrm{C}$ motifs present in polymers 7,8 and 9. All these polymers were readily soluble in water, $\mathrm{CH}_{3} \mathrm{OH}$ and ethanol. The intrinsic viscosities of the polymers 7, 8 and $\mathbf{9}$ were obtained from viscosities of $1-0.125 \%$ solutions in $0.1 \mathrm{M}$ $\mathrm{NaCl}$ at $30{ }^{\circ} \mathrm{C}$ using Mark-Huggins viscosity relationship. The intrinsic viscosities $[\eta]$ of $7, \mathbf{8}$ and $\mathbf{9}$ were determined to be $0.153,0.189$ and $0.174 \mathrm{dL} \mathrm{g}^{-1}$, respectively (Table 1 ). The relatively low intrinsic viscosity values indicated the low masses of the polymers. The TGA was used to study the degradation/ chemical stability of the synthesized polymers. The TGA curves for the polymers 7-9 (dried under vacuum at $55{ }^{\circ} \mathrm{C}$ for 12 h) revealed the weight losses at various temperature ranges (Fig. 4). A loss of $\approx 4-8 \%$ up to $190-220{ }^{\circ} \mathrm{C}$ accounted for the removal of moisture. An accelerated loss of an additional $\approx 40 \%$ for the polymers in the range $\approx 360-420{ }^{\circ} \mathrm{C}$ may be linked to the removal of different pendant groups. A major weight loss transition was observed at $220-450{ }^{\circ} \mathrm{C}$. A residual weight of $\approx 20 \%$ remained at $800{ }^{\circ} \mathrm{C}$. This variation in weight loss was because of the differences in the structures of the hard segments of the polymers. Overall, all these polymers were found to be stable up to $\approx 200{ }^{\circ} \mathrm{C}$.

\subsection{Corrosion evaluation}

3.2.1 Gravimetric measurements. The gravimetric weight loss measurements were used to study the corrosion inhibition efficiency of the synthesized polymers 7-9 in $1 \mathrm{M} \mathrm{HCl}$ at $60{ }^{\circ} \mathrm{C}$. Each experiment was performed in triplicate using mild steel coupons dipped in $250 \mathrm{~mL}$ of a $1 \mathrm{M} \mathrm{HCl}$ solution at $60{ }^{\circ} \mathrm{C}$ in the presence or absence of the polymer (7, 8 or 9), and the average values are reported in Table 2 . It is apparent from the gravimetric weight loss results (Table 2) that the inhibition efficiency increases with increasing concentrations of the polymers 7-9 in $1 \mathrm{M} \mathrm{HCl}$, and reached a maximum value at a higher concentration that indicated film formation on the mild steel surface. The results in Table 2 show that the measured inhibition efficiency values for 100 ppm of polymer compounds 7-9 were determined to be $87.6 \%, 99.5 \%$, and $82.3 \%$, respectively, whereas at a polymer concentration of $25 \mathrm{ppm}$, the corresponding inhibition efficiency values were found to be $82.3 \%$, $94.9 \%$ and $77.1 \%$, respectively. In all the concentrations of polymer compounds studied, copolymer 8 provided the best corrosion protection. At a concentration of $50 \mathrm{ppm}$, the inhibition efficiency value of the copolymer 8 was $99.4 \%$. The surface active functional motifs which had the $\mathrm{O}, \mathrm{N}$ and $\mathrm{S}$ centers present in polymer compound $\mathbf{8}$ were expected to
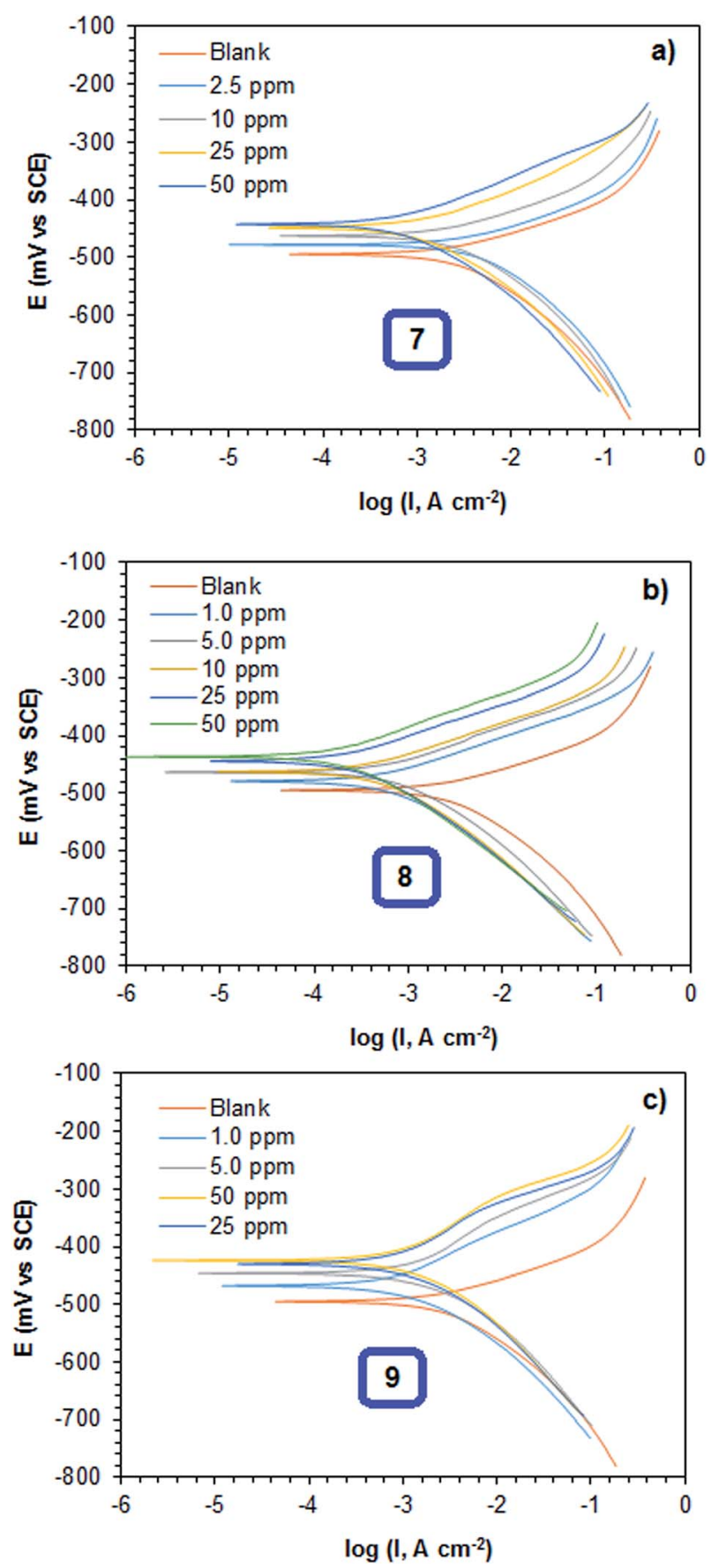

Fig. 6 Potentiodynamic polarization curves for mild steel inhibited with different concentrations of (a) 7, (b) 8 and (c) 9 at $60^{\circ} \mathrm{C}$ in $1 \mathrm{M} \mathrm{HCl}$. 
Table 3 Tafel and LPR results of a mild steel sample in $1 \mathrm{M} \mathrm{HCl}$ containing polymer compounds 7, 8 and 9 at different temperatures

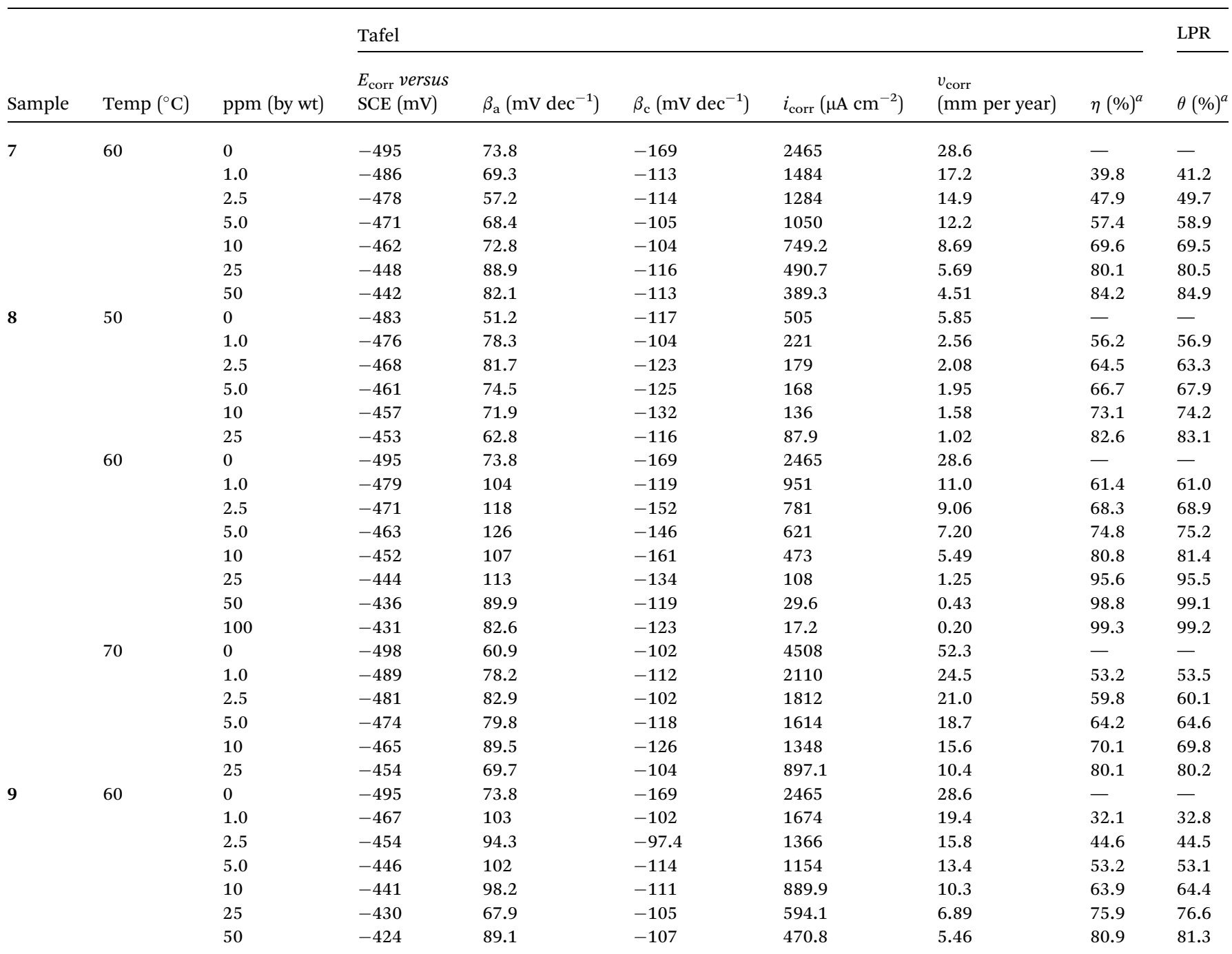

${ }^{a}$ Inhibition efficiency, (i.e., $\left.\eta\right)=$ surface coverage $\theta$.

provide a lone pair of electrons for the formation of coordinatetype bonds with the empty d-orbitals of the Fe or $\mathrm{Fe}^{2+}$ surface of mild steel to give the surface coverage by minimizing the van der Waals repulsive forces, and thus, prevent the corrosion attack on the mild steel surface.

3.2.2 Polarization measurements. The required time to reach the steady OCP values was obtained from the experiment measuring the OCP values versus immersion time for a mild steel specimen in the presence or absence (blank) of various polymers 7-9 at a concentration of $1.0 \mathrm{ppm}$ and $50 \mathrm{ppm}$ in $1 \mathrm{M}$ HCl solution. As shown in Fig. 5, the OCP values obtained in absence of polymer compounds, shifted slightly towards the positive direction, reached steady state in the shortest time, resulting in the free corrosion potential $E_{\text {corr }}$ of the mild steel. However, in the presence of different concentrations of polymers 7-9, the OCP values changed slowly towards the positive direction but with a higher magnitude, and reached a stable state after $\approx 20 \mathrm{~min}$. With increasing concentration of the polymers, the $E_{\text {corr }}$ value shifted towards a more positive direction, suggesting the preferential adsorption of polymer compounds was on the anodic sites of the mild steel metal surface. In the presence and absence of various concentrations of polymer compounds 7-9, the Tafel extrapolation plots for the mild steel samples were obtained after 45 min of immersion in $1 \mathrm{M} \mathrm{HCl}$ at $60^{\circ} \mathrm{C}$, and the results for this are shown in Fig. 6 . Different parameters such as current density of corrosion $\left(i_{\text {corr }}\right)$

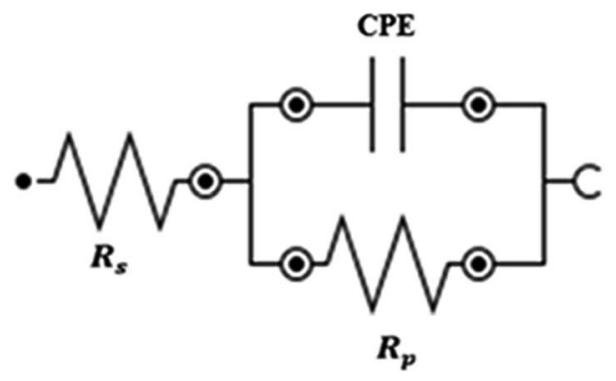

Fig. 7 Randles electrochemical equivalent circuit diagram. 
and corrosion potential ( $\left.E_{\text {corr }}\right)$ of mild steel were obtained from the extrapolated linear sections of the anodic and cathodic wings in the Tafel plots, and the results are presented in Table 3 . The decrease in $i_{\text {corr }}$ with an increase in concentration of the polymers, clearly indicates the inhibitive nature of the polymer compounds. As shown in Fig. 6 as well as in Table 3, the $E_{\text {corr }}$ values were shifted towards the positive direction for the synthesized polymer compounds $\mathbf{7 - 9}$ with a range in magnitude of 30-71 $\mathrm{mV}$ which suggested that the synthesized polymers could be classified as mixed type inhibitors. ${ }^{50}$ However, the greater reduction in anodic current densities (Table 3 ) indicated the greater decrease in the oxidation rate in the anodic reaction compared to the hydrogen evolution in the cathodic reaction. Under the greater influence of the anodic reaction, the polymer compounds covered the metal surface by the formation of a thin layer film, resulting in the retardation of metal dissolution from the metal surface. The results in Table 3 also show that no significant change or trend in cathodic $\left(\beta_{\mathrm{c}}\right)$ and/or anodic $\left(\beta_{\mathrm{a}}\right)$
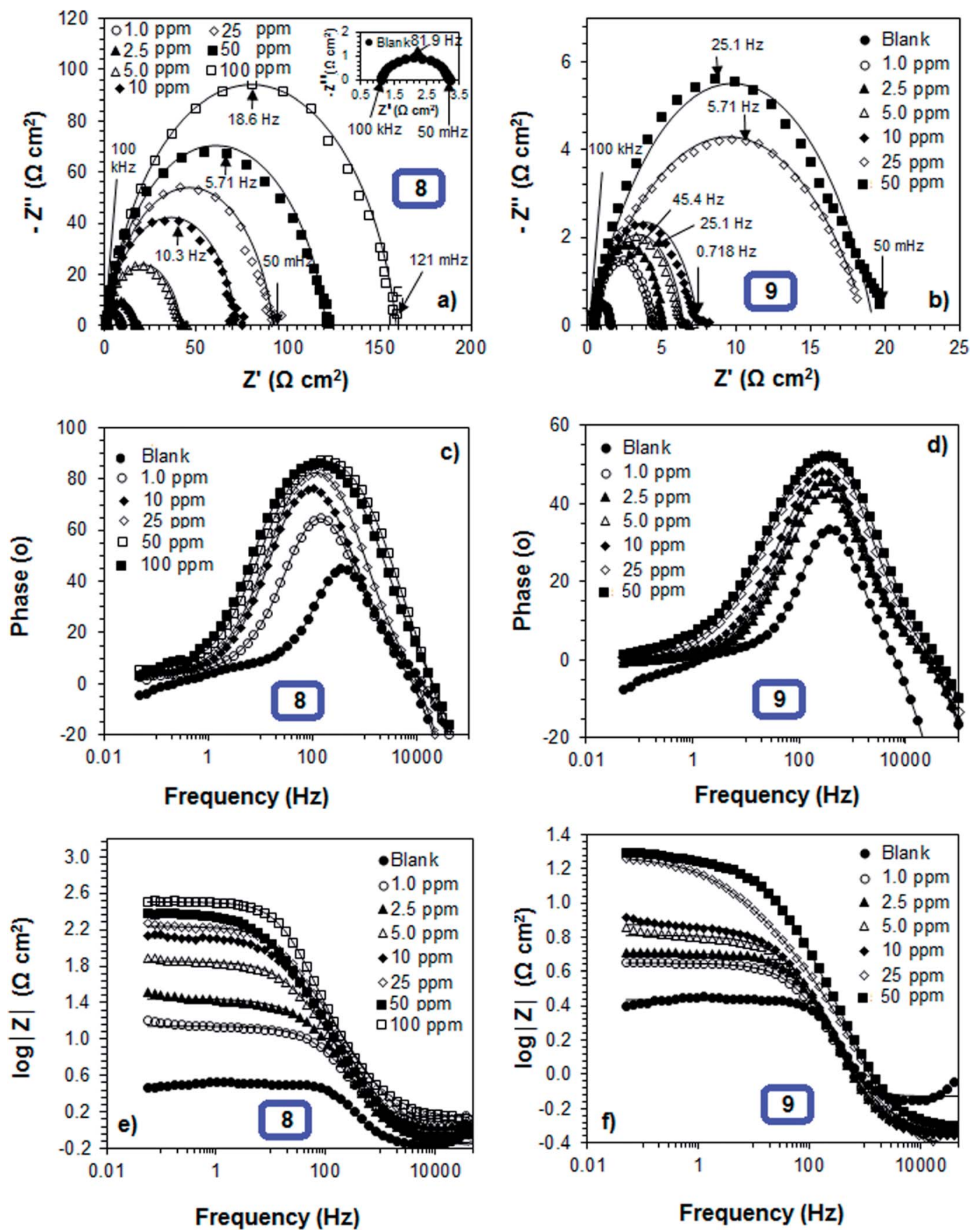

Fig. 8 Nyquist diagram of (a) 8 and (b) 9, Bode phase angle plots of (c) 8 and (d) 9 , and impedance plots (e) 8 and (f) 9 of mild steel inhibited with different concentrations at $60^{\circ} \mathrm{C}$ in $1 \mathrm{M} \mathrm{HCl}$. Various symbols represent experimental data and solid lines represent the Nyquist plot fitted to the equivalent circuit. 
slopes were observed. This was attributed to the fact that there was no change in inhibition mechanism by increasing the concentration of the polymers.

The corrosion inhibition efficiencies obtained from the Tafel and LPR methods are presented in Table 3. The inhibition efficiencies increased with increasing concentration of the polymers. The copolymer of DADMAC and the amino acid residue of cysteine 8 showed excellent inhibition efficiencies. It was extremely pleasing, that the inhibition efficiency of the copolymer was above the expected inhibition efficiency limit of the starting concentration for acid pickling. ${ }^{51}$ The inhibition efficiency obtained from the Tafel and LPR methods were in good agreement with the inhibition efficiencies calculated using the weight loss method (Table 2). The inhibitor efficiency of copolymer 8 was explored at different temperatures (50-70 $\left.{ }^{\circ} \mathrm{C}\right)$. The inhibition efficiency of the copolymer was found to be always higher than that of the individual homopolymer at all concentrations and temperatures. It was also found that the inhibition efficiency increased up to $60{ }^{\circ} \mathrm{C}$ with increasing concentration of the copolymers. With a further increase in temperature $\left(70{ }^{\circ} \mathrm{C}\right)$, the inhibition efficiency decreased. This could be because of the desorption of adsorbed copolymer, leading to a larger exposure of the metal to the acid solution, resulting in an increase in corrosion rate. ${ }^{52,53}$

3.2.3 Impedance measurements. The EIS measurements were performed after the immersion of mild steel in $1 \mathrm{M} \mathrm{HCl}$ for $45 \mathrm{~min}$. The best fitted Randles electrochemical equivalent circuit consisted of a solution resistance $\left(R_{\mathrm{S}}\right)$, polarization resistance $\left(R_{\mathrm{p}}\right)$ and a constant phase element (CPE) as shown in Fig. 7 which was utilized to obtain Nyquist and Bode plots in the presence or absence of various concentrations (0-100 ppm) of polymers, and the results are presented in Fig. 8. The electrochemical equivalent circuit parameters were obtained by fitting the data using Nova software (version 1.8). The electrochemical parameters of the fitted equivalent circuit were normalized using the specimen surface area $\left(2 \mathrm{~cm}^{2}\right)$, are given in Table 4 .

The $R_{\mathrm{s}}$ value was calculated from the intersection of the fitted semicircle with the real part $\left(Z^{\prime}\right)$ axis at high frequency. However, the $R_{\mathrm{p}}$ values were obtained from the intersection of the semicircle with the $Z^{\prime}$ axis at low frequency, by and other resistances such as the charge transfer resistance and diffusion layer resistance at the surface of working electrode also contributed to this value. ${ }^{54}$ Eqn (4) was used to calculate the net polarization resistance $\left(R_{\mathrm{p}}^{\prime}\right)$ :

$$
R_{\mathrm{p}}^{\prime}=R_{\mathrm{p}}-R_{\mathrm{s}}
$$

The $R_{\mathrm{p}}^{\prime}$ value obtained was later used in eqn (3) to calculate the inhibition efficiencies. The non-ideal capacitance and nonideal frequency response commonly used in the electrochemical circuit, was expressed by the CPE, and is related to the double layer capacitance $\left(C_{\mathrm{dl}}\right)$ using eqn (5):

$$
C_{\mathrm{d} 1}=\operatorname{CPE}(\omega)^{n-1}
$$

where $\omega$ and $n$ represent the angular frequency (radian) at the maximum imaginary part of the impedance, and surface heterogeneity, respectively.

The representative Nyquist and Bode plots of mild steel in the presence or absence of various concentrations of polymer compounds 8 and 9 in $1 \mathrm{M} \mathrm{HCl}$ at $60^{\circ} \mathrm{C}$ are shown in Fig. 8a-f. The appearance of the single semicircle increases with the

\begin{tabular}{|c|c|c|c|c|c|c|c|}
\hline Sample & Conc. ppm (by wt) & $R_{\mathrm{S}}\left(\Omega \mathrm{cm}^{2}\right)$ & $R_{\mathrm{p}}\left(\Omega \mathrm{cm}^{2}\right)$ & $\mathrm{CPE}^{a}\left(\mu \mathrm{F} \mathrm{cm}^{-2}\right)$ & $n$ & $R_{\mathrm{p}}^{\prime}\left(\Omega \mathrm{cm}^{2}\right)$ & $\eta(\%)$ \\
\hline \multirow[t]{5}{*}{7} & 0 & 0.373 & 1.963 & 922 & 0.976 & 1.590 & - \\
\hline & 1.0 & 0.368 & 3.054 & 497 & 0.912 & 2.686 & 40.8 \\
\hline & 5.0 & 0.326 & 4.214 & 403 & 0.827 & 3.888 & 59.1 \\
\hline & 10 & 0.329 & 5.393 & 324 & 0.783 & 5.064 & 68.6 \\
\hline & 25 & 0.311 & 8.067 & 276 & 0.760 & 7.756 & 79.5 \\
\hline & 1.0 & 0.423 & 4.479 & 132 & 0.922 & 4.056 & 60.8 \\
\hline & 2.5 & 0.407 & 5.553 & 106 & 0.901 & 5.146 & 69.1 \\
\hline & 5.0 & 0.365 & 7.046 & 79.8 & 0.876 & 6.681 & 76.2 \\
\hline & 10 & 0.351 & 9.385 & 68.1 & 0.843 & 9.034 & 82.4 \\
\hline & 25 & 0.329 & 34.89 & 57.3 & 0.796 & 34.56 & 95.4 \\
\hline & 50 & 0.204 & 227.3 & 29.4 & 0.769 & 227.1 & 99.3 \\
\hline & 10 & 0.372 & 4.876 & 357 & 0.817 & 4.504 & 64.7 \\
\hline & 25 & 0.325 & 6.762 & 285 & 0.782 & 6.437 & 75.3 \\
\hline & 50 & 0.268 & 9.101 & 105 & 0.769 & 8.833 & 82.0 \\
\hline
\end{tabular}

Table 4 Impedance parameters for the corrosion of mild steel samples in $1 \mathrm{M} \mathrm{HCl}$ solutions containing polymer compounds 7,8 and 9 at $60{ }^{\circ} \mathrm{C}$

${ }^{a}$ Double layer capacitance $\left(C_{\mathrm{dl}}\right)$ and coating capacitance $\left(C_{\mathrm{c}}\right)$ are usually modelled with a constant phase element (CPE) in modeling an electrochemical phenomenon. 
increasing concentrations of the polymer compounds, indicating that the acidic dissolution involves a single charge transfer mechanism, and the charge transfer process from mild steel to electrolyte becomes increasingly difficult with the increase in inhibitor concentration. Despite the similar trends of the semicircles observed for the polymer compounds 7-9, all the plots did not confirm perfect semicircles. This deviation from a typical semicircle could be because of the inhomogeneity and roughness of the mild steel surface..$^{55}$ The single maxima of the Bode phase angle plots (Fig. 8c and d) also supported the single charge transfer mechanism. The phase angle values appeared to be higher than the blank, indicating that the inhibitors adsorbed on the mild steel and electrolyte interfaces have some capacitive characteristics because of the formation of electric double layer.

The normalized EIS results for corrosion of a mild steel obtained from different concentrations of polymers 7-9 in $1 \mathrm{M}$ $\mathrm{HCl}$ at $60{ }^{\circ} \mathrm{C}$, and are presented in Table 4 . The Nova software (version 1.8) was used to fit the data to obtain the Randles equivalent circuit parameters. The $n$ values were found to be smaller than 1 (Table 4), and decreased with increasing concentration of the polymers, which indicated increased heterogeneity of the mild steel surface. As shown in the results in Table 4, the net polarization resistance increased with increase in the concentration of the polymers indicating the formation of a thin layer film on the mild steel surface. However, CPE values were decreased with increasing polymer concentrations, which might be because of the decrease in local dielectric constant and/or increase in the thickness of the electrical double layer, indicating that the polymer molecules strongly adsorbed onto the metal surface, and eventually lead to an increase in inhibition efficiency. ${ }^{56}$ The inhibition efficiency values for polymers 7,8 and 9 at a concentration $50 \mathrm{ppm}$ appeared to be $83.2,99.3$ and 82.0 , respectively after 45 min of mild steel immersion at $60{ }^{\circ} \mathrm{C}$. The results obtained from the EIS study were found to have good agreement with the results obtained from the Tafel, LPR, and gravimetric weight loss methods (see previous sections in this paper).

\subsection{Adsorption isotherms}

The inhibitive properties of a polymer compound depend on its surface active functionalities, which cause it to adsorb onto the mild steel metal surface. The polymer compounds 7-9 were subjected to gravimetric as well as electrochemical methods to determine the surface coverage $(\theta)$, and the data are shown in Tables 2-4. It was noted that fractional inhibition efficiency $\eta$ and surface coverage $\theta$ were usually found to be linear at lower concentrations of an inhibitor molecule. However, the values deviated at higher concentrations, which could be attributed to
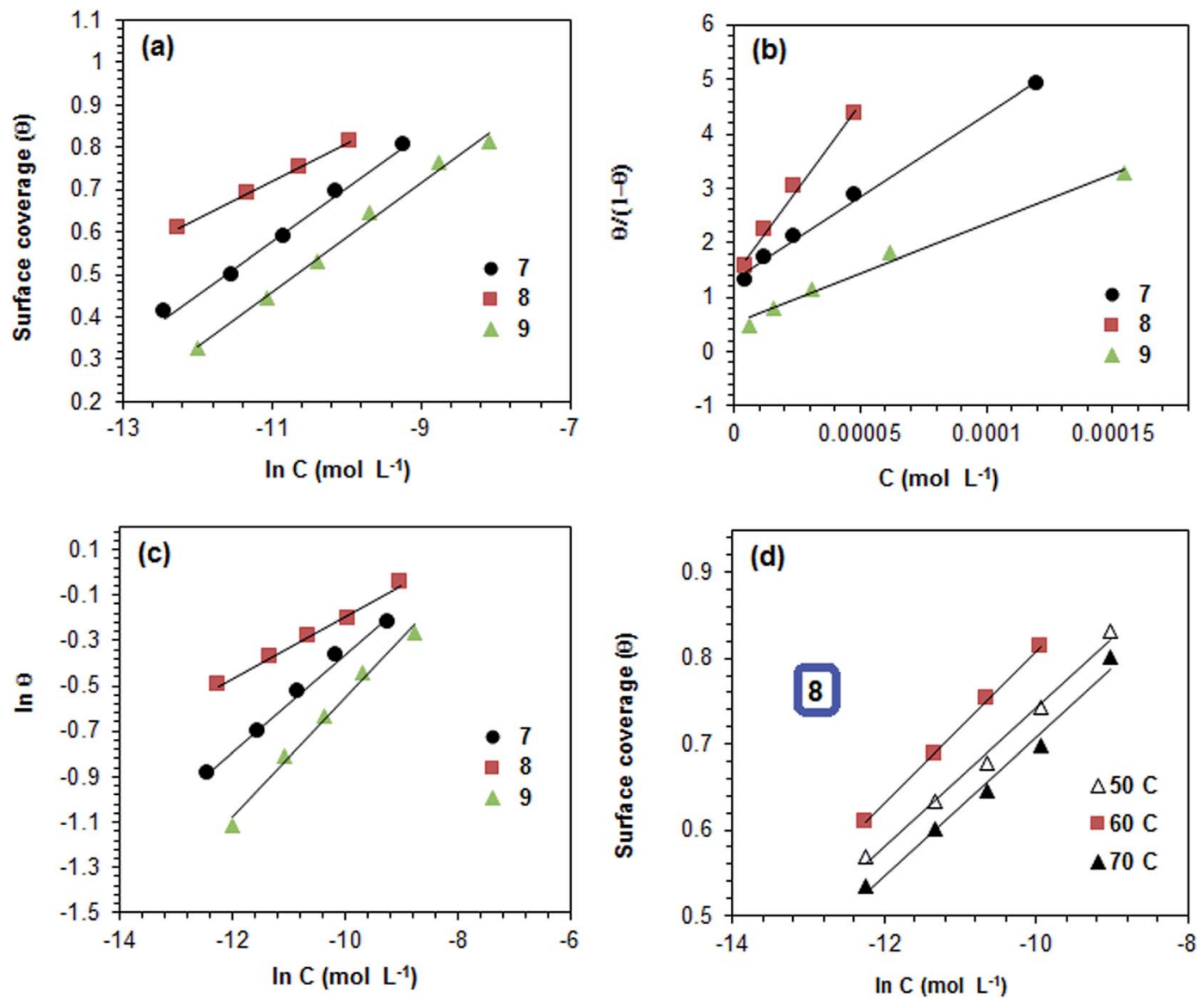

Fig. 9 (a) Temkin, (b) Langmuir, and (c) Freundlich adsorption isotherms for the adsorption of polymers $7-9$ at $60^{\circ} \mathrm{C}$, and (d) Temkin adsorption isotherm for the adsorption of inhibitor 9 at various temperatures, on the surface of mild steel. 
Table 5 Square correlation coefficient $\left(R^{2}\right)$ and constant adsorption isotherm values of Temkin, Frumkin, Langmuir and Freundlich in the presence of polymer compounds 7, 8 and 9 in $1 \mathrm{M} \mathrm{HCl}$ solution (LPR data used for the isotherm)

\begin{tabular}{|c|c|c|c|c|c|}
\hline Sample & Temp $\left({ }^{\circ} \mathrm{C}\right)$ & $\operatorname{Temkin}^{a}\left(R^{2}, f\right)$ & Langmuir $^{b}\left(R^{2}\right)$ & Frumkin $^{c}\left(R^{2}, a\right)$ & Freundlich $^{d}\left(R^{2}, n\right)$ \\
\hline 7 & 60 & $0.9934,8.0$ & 0.9921 & $0.9507,-0.1$ & $0.9948,0.2$ \\
\hline \multirow[t]{2}{*}{8} & 50 & $0.9917,12$ & 0.9952 & $0.9573,-0.1$ & $0.9986,0.1$ \\
\hline & 70 & $0.9905,12$ & 0.9949 & $0.9418,-0.1$ & $0.9953,0.1$ \\
\hline 9 & 60 & $0.9981,7.3$ & 0.9890 & $0.9837,-1.5$ & $0.9888,0.3$ \\
\hline
\end{tabular}

Table 6 The adsorption equilibrium constant values from Temkin adsorption isotherms and free energy, enthalpy, entropy changes of the mild steel dissolution in the presence of polymer compounds 7, 8 and 9 in $1 \mathrm{M} \mathrm{HCl}$

\begin{tabular}{|c|c|c|c|c|c|}
\hline Sample & Temp $\left({ }^{\circ} \mathrm{C}\right)$ & $K_{\mathrm{ads}}\left(\mathrm{L} \mathrm{mol}^{-1}\right)^{a}$ & $\Delta G_{\mathrm{ads}}^{\circ}\left(\mathrm{kJ} \mathrm{mol}^{-1}\right)$ & $\Delta H_{\mathrm{ads}}^{\circ}\left(\mathrm{kJ} \mathrm{mol}^{-1}\right)$ & $\Delta S_{\text {ads }}^{\circ}\left(\mathrm{J} \mathrm{mol}^{-1} \mathrm{~K}^{-1}\right)$ \\
\hline 7 & 60 & 60.92 & -41.9 & - & - \\
\hline \multirow[t]{2}{*}{8} & 50 & 2088 & -51.4 & & \\
\hline & 70 & 1389 & -50.3 & & \\
\hline 9 & 60 & 16.93 & -38.5 & - & - \\
\hline
\end{tabular}

the change from monolayer surface coverage to a multilayer surface. The inhibition efficiency values obtained using LPR (Table 3) and the corresponding concentrations $C$ were used to fit the commonly used adsorption isotherms (i.e., Freundlich, Langmuir, Frumkin and Temkin isotherms) described elsewhere in the literature. ${ }^{57}$ The representative adsorption isotherms obtained using the linear least square method are presented in Fig. 9a-d.

The synthesized polymer compounds 7-9 were tested for different adsorption isotherms, and the constant values obtained from different adsorption isotherms and their square correlation coefficients $\left(R^{2}\right)$ are presented in Table 5 . The synthesized polymer molecules 7-9 demonstrated higher $R^{2}$ values and were found to be the best fit for the Temkin and Freundlich adsorption isotherms, which implied physisorption through an electrostatic interaction between the surface of mild steel and solution interface in which the polymer molecules also contributed to the adsorption process. The higher $R^{2}$ values of the straight lines also obtained by using the Langmuir isotherm model, indicated the adsorption of inhibition was achieved predominantly by chemisorption.

Using eqn (6) and (7), the thermodynamic parameters (adsorption equilibrium constant $\left(K_{\text {ads }}\right)$, free energy $\left(\Delta G_{\text {ads }}^{\circ}\right)$, enthalpy $\left(\Delta H_{\text {ads }}^{\circ}\right)$ and entropy of adsorption $\left(\Delta S_{\text {ads }}^{\circ}\right)$ ) were calculated to further understand the adsorption mechanism:

$$
\begin{gathered}
K_{\mathrm{ads}}=\frac{1}{55.5} \exp \left(\frac{-\Delta G_{\mathrm{ads}}^{\circ}}{R T}\right) \\
\Delta G^{0}=\Delta H^{0}-T \Delta S^{0} .
\end{gathered}
$$

The obtained thermodynamic parameters are presented in Table 6 .
The results in Fig. 10 show that the $\Delta G_{\text {ads }}^{\circ}$ and $\Delta H_{\text {ads }}^{\circ}$ were negative, which suggested that the adsorption process was spontaneous and exothermic. Depending on the magnitude of $\Delta G_{\text {ads }}^{\circ}$ and $\Delta H_{\text {ads }}^{\circ}$, the mechanism of adsorption can be categorized as physisorption, chemisorption or a mixed mechanism. .8-61 $^{-1}$

As shown in Table 6 , the $\Delta G_{\text {ads }}^{\circ}$ values for the polymer compounds 7-9 were found to be in the range -38.5 and $-51.4 \mathrm{~kJ} \mathrm{~mol}^{-1}$, and the $\Delta H_{\mathrm{ads}}^{\circ}$ value for polymer compound 8 was found to be $-69.2 \mathrm{~kJ} \mathrm{~mol}^{-1}$. These similar values suggest that the adsorption process for the polymer compounds occurred through a mixed mechanism with predominantly chemisorption. The synthesized polymer compounds with $\pi$ and non-bonded electrons, were capable of following electrostatic and chemical interaction with the anodic sites by

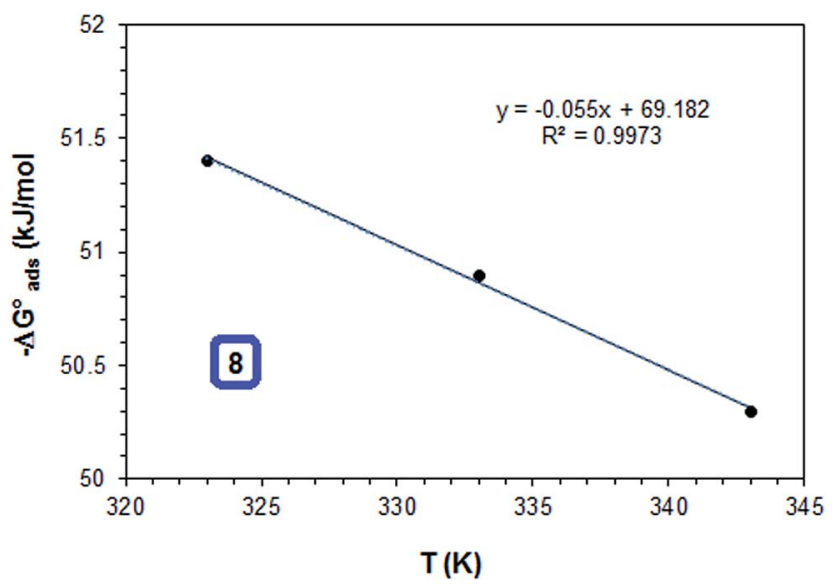

Fig. 10 Variation of $-\Delta G_{\text {ads }}^{\circ}$ versus $T$ on mild steel inhibited by copolymer 8 in $1 \mathrm{M} \mathrm{HCl}$. 
overlapping with the low lying vacant d-orbitals of iron. ${ }^{62,63}$ Upon adsorption of polymer compound $\mathbf{8}$ onto the mild steel surface, the calculated $\Delta S_{\text {ads }}^{\circ}$ value was found to be $55 \mathrm{~J} \mathrm{~mol}^{-1}$ $\mathrm{K}^{-1}$ (Fig. 10, Table 6). This finding suggested that the polymer compound was adsorbed onto the metal surface and displaced the adsorbed water molecules from the surface of the mild steel, and increased the randomness on the solid surface/inhibitor interface.

\subsection{Surface characterization}

The gravimetric weight loss and various electrochemical methods indicated that the synthesized polymer compounds were able to form a thin film on the mild steel metal surface and this resisted corrosion attack. To better visualize and realize the film forming ability and surface morphologies of the polymeric materials studied, the surface of the mild steel in the presence and absence of the synthesized polymer compounds were explored using AFM, EDX, SEM and XPS.

3.4.1 AFM. The surface topographies of the polished mild steel and mild steel in $1 \mathrm{M} \mathrm{HCl}$ solution in the presence and absence of polymer compounds were studied using AFM. The AFM images of polished mild steel and mild steel exposed to $1 \mathrm{M} \mathrm{HCl}$ in the presence or absence of polymer compound $\mathbf{8}$ are shown in Fig. 11a-c. The surface of the polished mild steel was relatively smooth (Fig. 11a), with an average roughness $\left(R_{\mathrm{a}}\right)$ value of $27 \mathrm{~nm}$. After exposure to $1 \mathrm{M} \mathrm{HCl}$ for $6 \mathrm{~h}$, it is clearly shown in Fig. 11b that the mild steel sample was severely damaged because of the acid attack on the mild steel surface, and the surface roughness increased to $329 \mathrm{~nm}$. However, in the presence of polymer compound 8 at a concentration of $100 \mathrm{ppm}$ as shown in Fig. 11c, the average roughness was reduced to $33 \mathrm{~nm}$. The lower value of calculated roughness in presence of polymer compound $\mathbf{8}$ indicated that the polymer compound $\mathbf{8}$ formed a thin film layer and efficiently protected the mild steel surface.

3.4.2 SEM-EDX analysis. The surface morphology of the polished mild steel in the presence and absence of polymer compound 8 in $1 \mathrm{M} \mathrm{HCl}$ at $60{ }^{\circ} \mathrm{C}$ for $6 \mathrm{~h}$ was examined using SEM-EDX, and the results are shown in Fig. 12a-c. The SEM image of the polished mild steel coupon (Fig. 12a) shows a relatively smooth surface. However, after immersion of the mild steel in $1 \mathrm{M} \mathrm{HCl}$ for $6 \mathrm{~h}$, the mild steel coupons were severely damaged and become very porous (Fig. 12b). When the mild steel coupons were dipped in $1 \mathrm{M} \mathrm{HCl}$ containing $100 \mathrm{ppm}$ of polymer $\mathbf{8}$, the mild steel coupon surface appeared to be relatively smooth (Fig. 12c), which was comparable to the polished surface (Fig. 12a). This is attributed to the fact that the polymer compound formed a thin layer film by adsorption and reduced the accessibility of the acid solution to the mild steel metal surface. To realize the structural composition of the thin film formed by the polymer compound, EDX analysis was performed, and the results are shown in Fig. 12d-f. The strong iron signal (Fig. 12d) appeared in an iron rich polished mild steel surface. However, $1 \mathrm{M} \mathrm{HCl}$ exposed to an untreated mild steel coupon showed oxygen and iron signals. This could be attributed to atmospheric oxidation and/or formation of iron oxide
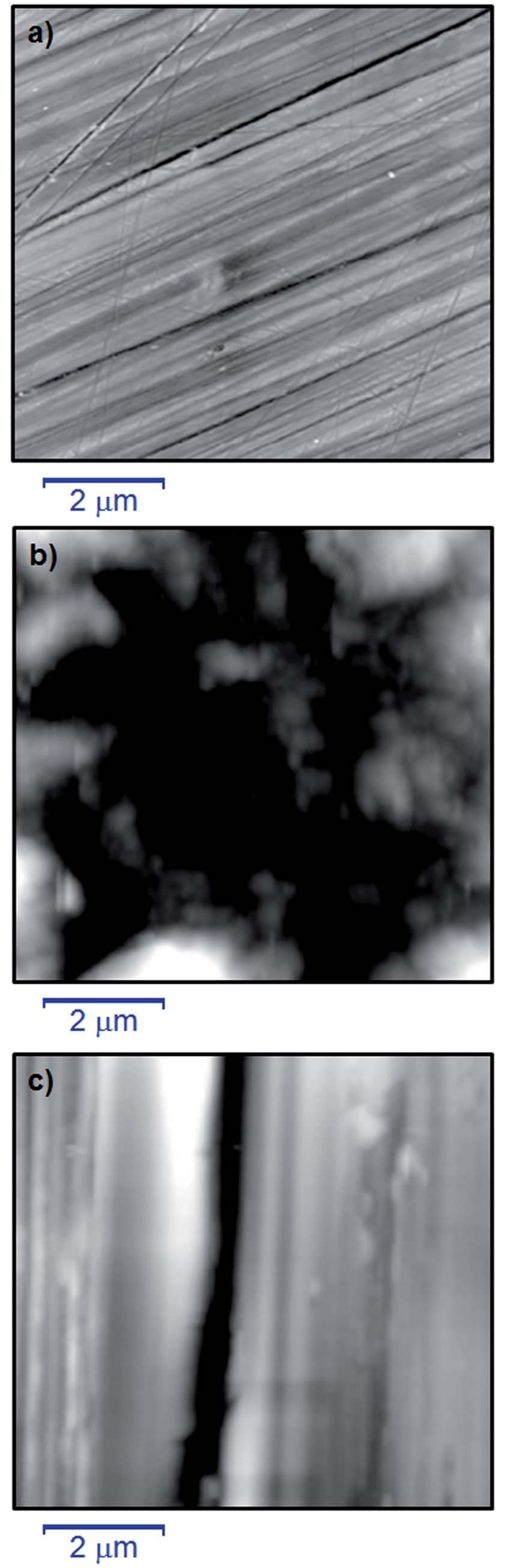

Fig. 11 AFM images of mild steel: (a) polished; immersion for $6 \mathrm{~h}$ in (b) $1 \mathrm{M} \mathrm{HCl}$, and (c) $100 \mathrm{ppm}$ of polymer compound 8 in $1 \mathrm{M} \mathrm{HCl}$. 


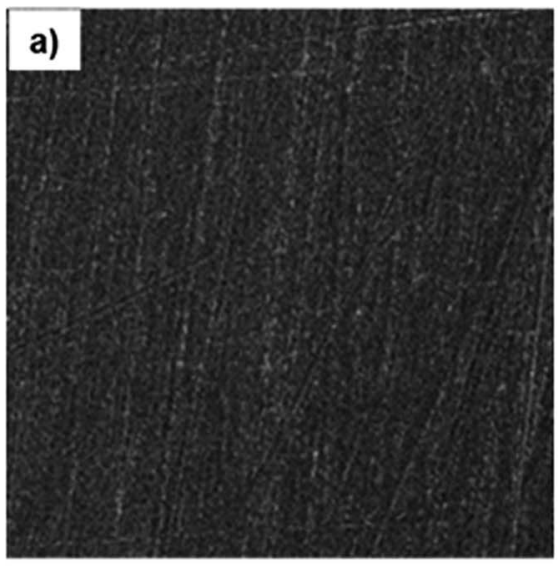

$500 \mu \mathrm{m}$
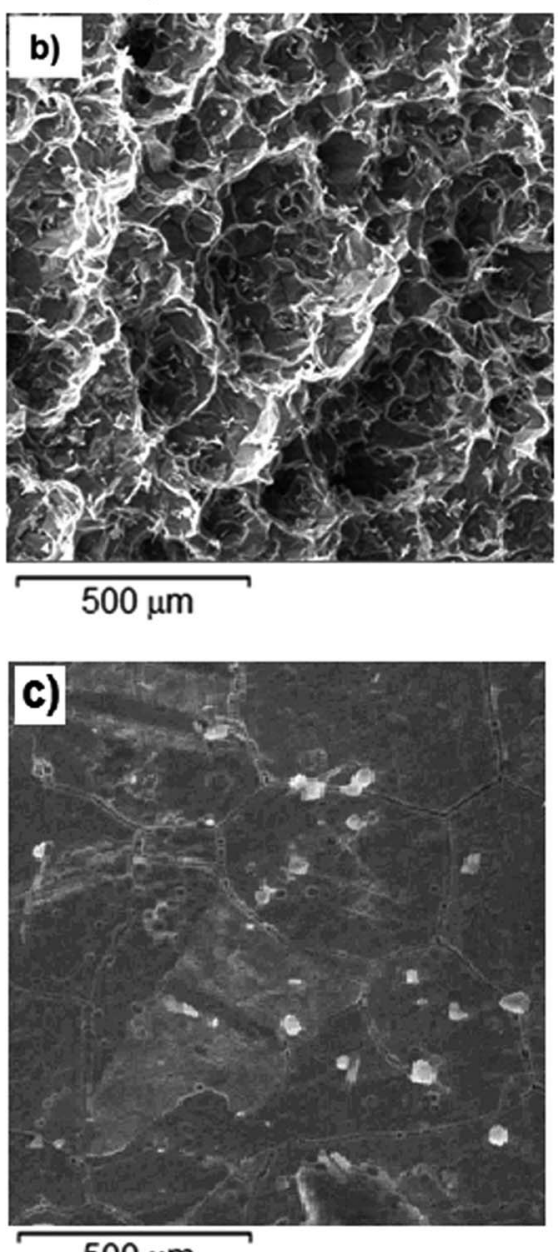

$500 \mu \mathrm{m}$

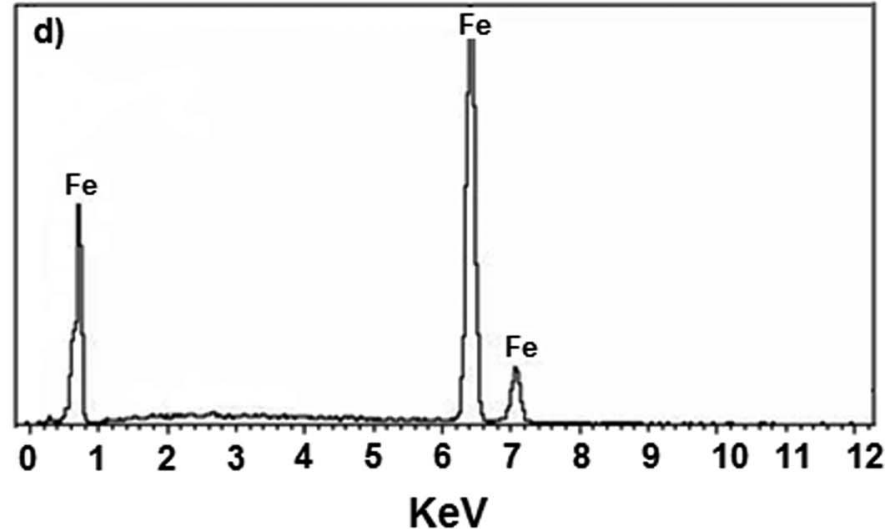

e)
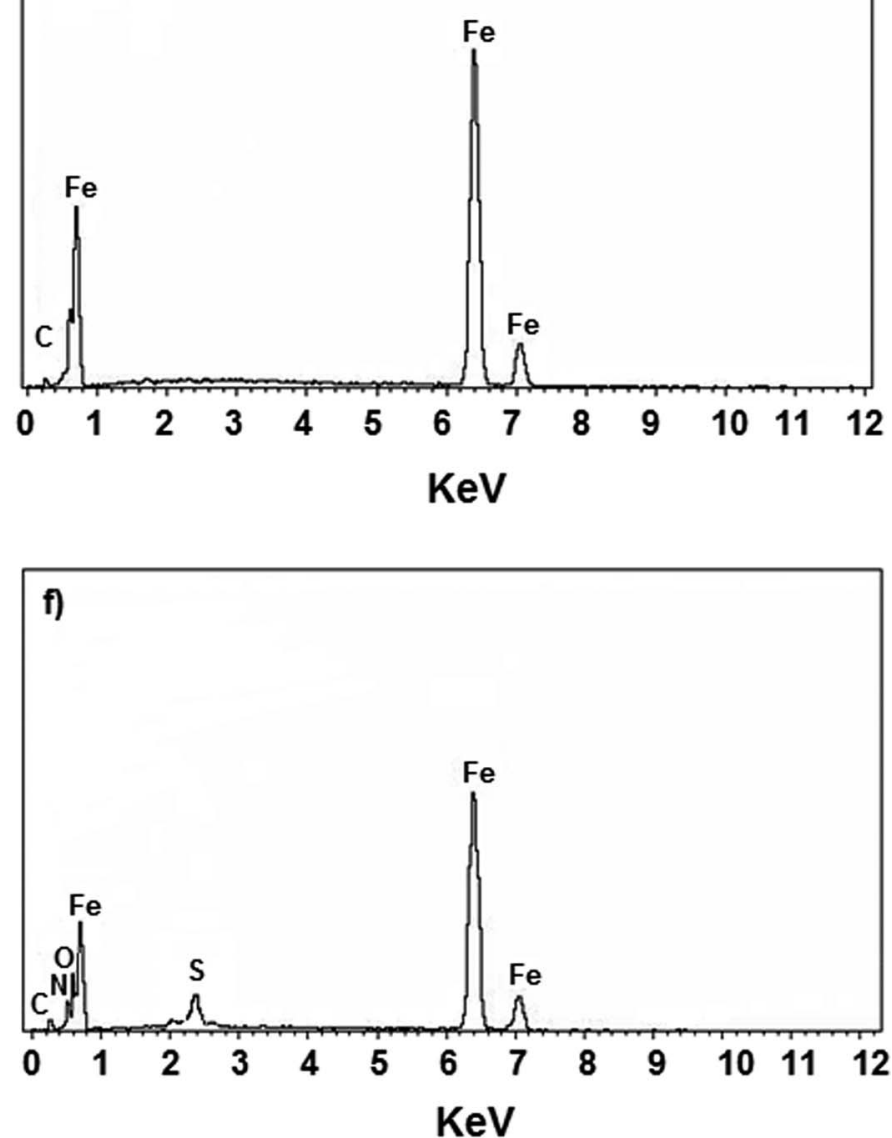

Fig. 12 SEM images and EDX spectra of mild steel surface: (a and d) polished, after immersion for $6 \mathrm{~h}$ in: $(\mathrm{b}$ and e) untreated mild steel in $1 \mathrm{M} \mathrm{HCl}$, and ( $c$ and f) mild steel treated in presence of 100 ppm of copolymer 8 .

$\left(\mathrm{Fe}_{2} \mathrm{O}_{3}\right)$ films onto the mild steel metal surface (Fig. 12e). The C, N, O, S atoms and decreased iron signal (Fig. 12f) appeared on the inhibited mild steel surface, which clearly indicated that the polymer compound $\mathbf{8}$ had been adsorbed and formed a thin film on the metal surface, and resisted corrosion in aggressive media.
3.4.3 XPS analysis. Fig. 13a and b display the full XPS spectrum of a mild steel sample enclosed by the polymer compounds 7 and 8 at a concentration of $100 \mathrm{ppm}$ after immersion for $6 \mathrm{~h}$ at $60^{\circ} \mathrm{C}$. The high resolution XPS spectrum of polymer compounds 7, 8 and 9 showing S 2p, Fe 2p, C 1s and O 1s can be seen in Fig. 13c-f. The representative peaks and their 

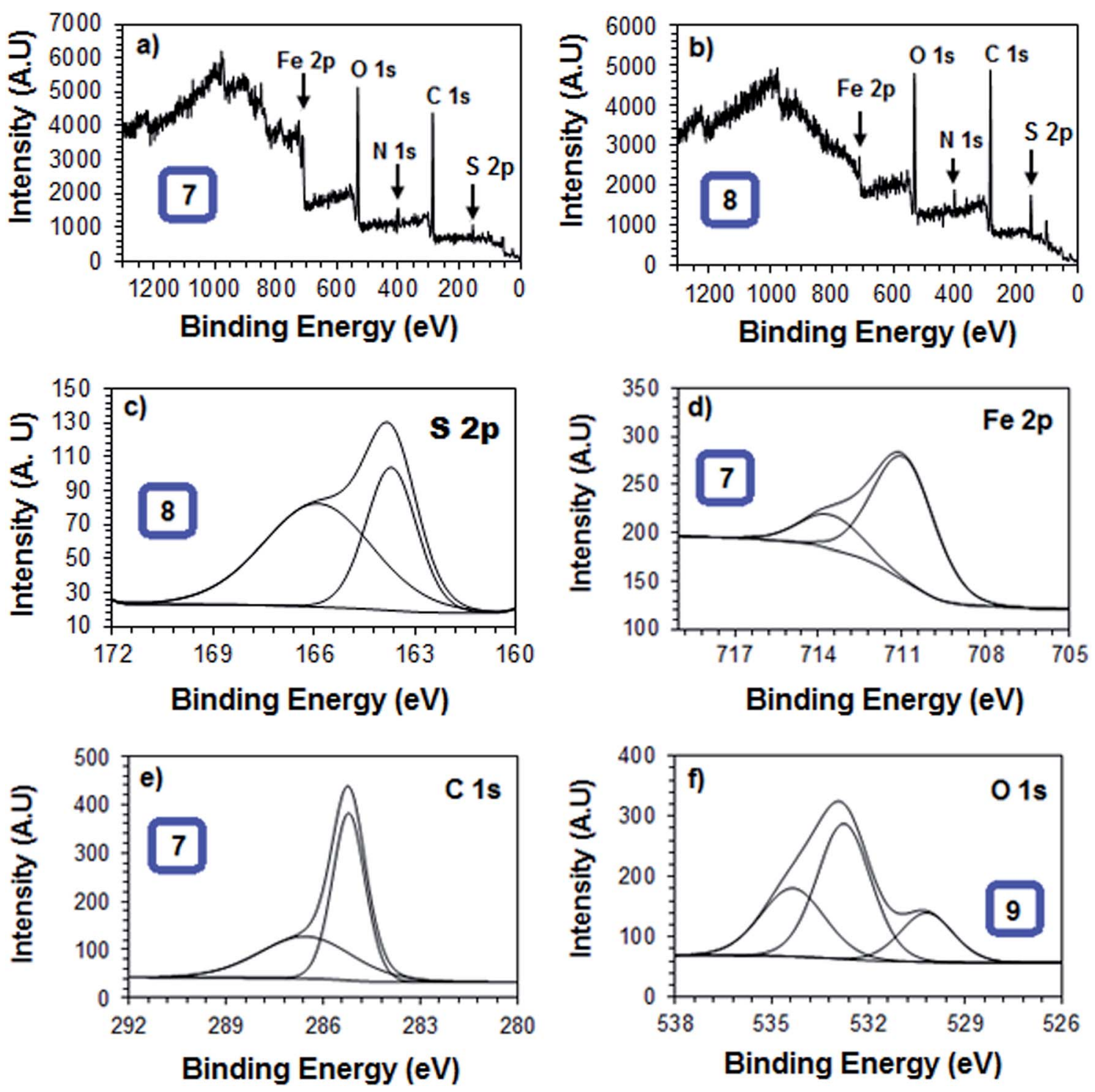

Fig. 13 XPS survey spectrum of (a) 7 and (b) 8, and high resolution XPS spectra of deconvoluted profiles of (c) S 2p of 8, (d) Fe 2p of 7, (e) C 1s of 7, and (f) $\mathrm{O}$ 1s of 9 . Conditions: immersion time: $6 \mathrm{~h}$, concentration: $100 \mathrm{ppm}$ in $1 \mathrm{M} \mathrm{HCl}$ and temperature: $60^{\circ} \mathrm{C}$.

atomic percentage compositions are shown in Table 7 . According to the results shown in Fig. 13a and $b$, higher intensity signals of S 2p, N 1s, C 1s, O 1s and Fe 2p were detected on the inhibited mild steel metal surface, which provided further evidence of the polymer compound adsorbing onto the metal surface. For high resolution XPS spectra, the sulfide functionalities of polymer compound $\mathbf{8}$ appeared as $\mathrm{S} 2 \mathrm{p}$ signals at 163.6 and $166.2 \mathrm{eV}$ (ref. 64) (Fig. 13c). The intensity signals appearing at 707.3 and $713.8 \mathrm{eV}$ can be assigned to $\mathrm{Fe}^{3+}(2 \mathrm{p})$ and $\mathrm{Fe}^{0}$ (2p), respectively, (Fig. 13d). The main contribution of the C-C aliphatic peak, and COO- peaks (Fig. 13e) appearing at 285.4 and $286.6 \mathrm{eV}$, respectively, can be attributed to the characteristic peaks of the polymer compounds. ${ }^{65,66}$ The bonding state of $\mathrm{O}^{2-}$ and $\mathrm{O}=\mathrm{O}$ at 530.2 and $532.0 \mathrm{eV}$, respectively, were attributed to the characteristic peak of oxygen indicating the formation of a thin film as a result of partial oxidation, and deposition of the polymer compound onto the metal surface
Table 7 XPS survey results for a mild steel coupon immersed for $6 \mathrm{~h}$ in $1 \mathrm{M} \mathrm{HCl}$ containing $50 \mathrm{ppm}$ of 7,8 and 9 at $60^{\circ} \mathrm{C}$

\begin{tabular}{lllll}
\hline & & \multicolumn{3}{c}{ Composition (atom\%) } \\
\cline { 4 - 5 } Peak & $\begin{array}{l}\text { Approximate binding } \\
\text { energy }(\mathrm{eV})\end{array}$ & 7 & $\mathbf{8}$ & $\mathbf{9}$ \\
\hline C 1s & 285.3 & 34.9 & 30.8 & 24.7 \\
C 1s & 286.7 & 24.8 & 32.7 & 37.9 \\
O1s & 530.3 & 3.95 & 10.5 & 5.71 \\
O 1s & 532.8 & 27.1 & & 16.0 \\
O 1s & 533.1 & & 19.4 & 9.54 \\
N 1s & 400.9 & 5.13 & 4.06 & 3.23 \\
Fe 2p & 707.3 & & 0.19 & \\
Fe 2p & 710.6 & 2.15 & 1.89 & 1.42 \\
Fe 2p & 713.9 & 0.69 & 0.41 & 0.78 \\
Cl 2p & 198.5 & 1.35 & & 0.76
\end{tabular}


(Fig. 13f). ${ }^{67,68}$ These individual signals proved that polymer compound $\mathbf{8}$ formed a thin layer film which covered the mild steel metal surface.

\section{Conclusions}

Butler's cyclopolymerization of diallylammonium salts was used to synthesize homo and copolymers 7-9 based on DADMAC and the amino acid residue of cysteine, in excellent yields. The TGA results suggested that the synthesized polymers were stable up to $200{ }^{\circ} \mathrm{C}$. The results of an inhibition efficiency study conducted using a gravimetric method, potentiodynamic polarization, and EIS suggested that the synthesized copolymers containing unquenched nitrogen and sulfur valences performed excellently in $1 \mathrm{M} \mathrm{HCl}$ in mitigating mild steel corrosion. The inhibition efficiency increases with increasing concentration of the polymers. The inhibiting performance of copolymer is found to be better than that of the homopolymers. The EIS measurements showed that the net polarization increases and the CPE values were decreased with increasing concentrations of the polymers, indicating that the polymer molecules were adsorbed onto the metal surface. The Temkin, Langmuir and Freundlich adsorption isotherm models and the results of different surface morphology studies obtained using AFM, SEM and XPS suggested that the inhibition process mainly occurred through an adsorption process. This systematic study might provide a way to design a new corrosion inhibitor that could lead to a better understanding of different techniques for the evaluation of corrosion, of corrosion inhibitors and be beneficial for biomedical as well as oil and gas industries.

\section{Conflicts of interest}

There are no conflicts to declare.

\section{Acknowledgements}

The author gratefully acknowledge the research facilities provided by King Fahd University of Petroleum and Minerals (KFUPM) and the financial assistance of Saudi Aramco, EXPEC Advanced Research Center, Dhahran, Saudi Arabia through project \# (CHEM 2414) and CRPO \# 6510847776.

\section{References}

1 C. Volkan, Corrosion Chemistry, John Wiley \& sons, New Jersey, 2011.

2 C. Volkan and B. J. Al-Numan, Corros. Chem., 2012, vol. 68, pp. 84-86.

3 R. W. Revie and H. H. Uhlig, Corrosion and Corrosion Control, John Wiley \& Sons, New Jersey, 2008.

4 A. Singh, I. Ahamad, D. K. Yadav, V. K. Singh and M. A. Quraishi, Chem. Eng. Commun., 2012, 199, 63-77.

5 W. Durnie, B. Kinsella, R. De Marco and A. Jefferson, J. Electrochem. Soc., 1999, 146, 1751-1756.
6 F. Bentiss, M. Lagrenee and M. Traisnel, Corros. Sci., 2000, 56, 733-742.

7 J. Mosa, N. C. Rosero-Navarro and M. Aparicio, RSC Adv., 2016, 6, 39577-39586.

8 K. R. Ansari, M. A. Quraishi and A. Singh, Corros. Sci., 2015, 95, 62-70.

9 S. A. Odoemelam and N. O. Eddy, J. Surf. Sci. Technol., 2008, 24, 65-78.

10 M. Finšgar and J. Jackson, Corros. Sci., 2014, 86, 17-41.

11 G. Gece, Corros. Sci., 2011, 53, 3873-3898.

12 K. R. Ansari, M. A. Quraishi and A. Singh, Corros. Sci., 2014, 79, 5-15.

13 M. Bethencourt, F. J. Botana, J. J. Calvino, M. Marcos and M. A. Rodriguez-Chacon, Corros. Sci., 1998, 40, 1803-1819.

14 B. R. W. Hinton, J. Alloys Compd., 1992, 180, 15-25.

15 S. N. Tiwari and S. Prakash, J. Mater. Sci. Technol., 1998, 14, 467-472.

16 W. Revie and H. H. Uhlig, Corrosion and Corrosion Control: An Introduction to Corrosion Science and Engineering, WileyInter science, NY, USA, 2008.

17 Y. Tang, X. Yang, W. Yang, Y. Chen and R. Wan, Corros. Sci., 2010, 52, 242-249.

18 A. A. F. Sabirneeza, R. Geethanjali and S. Subhashini, Chem. Eng. Commun., 2015, 202, 232-244.

19 S. H. Zaferani, M. Sharifi, D. Zaarei and M. R. Shishesaz, J. Environ. Chem. Eng., 2013, 1, 652-657.

20 R. Rajalakshmi, A. Prithiba and S. Leelavathi, J. Chem. Acta, 2012, 1, 6-13.

21 Sustainable Catalysis: Challenges and Practices for the Pharmaceutical and Fine Chemical Industries, ed. P. J. Dunn, K. K. Hii, M. J. Krische and M. T. Williams, Wiley, Weinheim, 2013.

22 R. A. Sheldon, Green Chem., 2014, 16, 950-963.

23 C. Verma, L. O. Olasunkanmi, E. E. Ebenso, M. A. Quraishi and I. B. Obot, J. Phys. Chem. C, 2016, 120, 11598-11611.

24 H. Zhao, X. Zhang, L. Ji, H. Hud and Q. Li, Corros. Sci., 2014, 83, 261-271.

25 B. A. Abd-El-Nabey, N. Khalil and A. Mohamed, Surf. Technol., 1985, 24, 383-389.

26 H. Ashassi-Sorkhabia, M. R. Majidib and K. Seyyedi, Appl. Surf. Sci., 2004, 225, 176-185.

27 M. A. Amin, K. F. Khaled, Q. Mohsen and H. A. Arida, Corros. Sci., 2010, 52, 1684-1695.

28 K. Barouni, L. Bazzi, R. Salghi, M. Mihit, B. Hammouti, A. Albourine and S. El-Issami, Mater. Lett., 2008, 262, 3325-3327.

29 M. S. S. Morad, A. E. H. A. Hermas and M. S. A. Aal, J. Chem. Technol. Biotechnol., 2002, 77, 486-494.

30 K. M. Ismail, Electrochim. Acta, 2007, 52, 7811-7819.

31 M. S. El-Deab, Mater. Chem. Phys., 2011, 129, 223-227.

32 H. Saifi, M. C. Bernard, S. Joiret, K. Rahmouni, H. Takenouti and B. Talhi, Mater. Chem. Phys., 2010, 120, 661-669.

33 N. H. Helal and W. A. Badawy, Electrochim. Acta, 2011, 56, 6581-6587.

34 M. Mobin, S. Zehra and M. Parveen, J. Mol. Liq., 2016, 216, 598-607. 
35 G. Markevicius, S. Chaudhuri, C. Bajracharya, R. Rastogi, J. Xiao, C. Burnett and T. Q. Chastek, Prog. Org. Coat., 2012, 75, 319--327.

36 S. Kumar, H. Vashisht, L. O. Olasunkanmi, I. Bahadur, H. Verma, M. Goyal, G. Singh and E. E. Ebenso, Ind. Eng. Chem. Res., 2017, 56, 441--456.

37 R. Baskar, M. Gopiraman, D. Kesavan, K. Subramanian and S. Gopalakrishnan, J. Mater. Eng. Perform., 2015, 24, 2847-2856 .

38 Y. Jianguo, W. Lin, V. Otieno-Alego and D. P. Schweinsberg, Corros. Sci., 1995, 37, 975-985.

39 S. Prakash, C. R. K. Rao and M. Vijayan, Electrochim. Acta, 2008, 53, 5704--5710.

40 G. B. Butler, Cyclopolymerization and cyclocopolymerization, Marcel Dekker, NY, USA, 1992.

41 P. K. Singh, V. K. Singh and M. Singh, E Polymer, 2007, 30, 134.

42 H. A. Al-Muallem, M. A. J. Mazumder, M. K. Estaitie and S. A. Ali, Iran. Polym. J., 2015, 24, 541-547.

43 W. Jaeger, J. Bohrisch and A. Laschewsky, Prog. Polym. Sci., 2010, 35, 511-577.

44 S. A. Ali, S. A. Haladu and A. M. Z. El-Sharif, J. Polym. Res., 2016, 23, 167-176.

45 S. A. Ali and O. C. S. Al-Hamouz, Polymer, 2012, 53, 33683377.

46 A. V. Raghu, G. S. Gadaginamath, N. Mathew, S. B. Halligudi and T. M. Aminabhavi, J. Appl. Polym. Sci., 2007, 106, 299308.

47 A. V. Raghu, G. Anita, Y. M. Barigaddi, G. S. Gadaginamath and T. M. Aminabhavi, J. Appl. Polym. Sci., 2007, 104, 81-88.

48 D. P. Suhas, H. M. Jeong, T. M. Aminabhavi and A. V. Raghu, Polym. Eng. Sci., 2014, 54, 24-32.

49 S. Kudaibergenov, W. Jaeger and A. Laschewsky, Adv. Polym. Sci., 2006, 201, 157-224.

50 S. Z. Duan and Y. L. Tao, Interface Chemistry, Higher Education Press, Beijing, 1990.

51 H. Keleş, M. Keleş, I. Dehri and O. Serindağ, Colloids Surf., A, 2008, 320, 138-145.
52 G. N. Devi, J. Saranya, N. Manjubaashini, T. D. Thangadurai, S. M. Roopan and S. Chitra, Prog. Org. Coat., 2017, 109, 117125.

53 H. Zarrok, H. Oudda, A. Zarrouk, R. Salghi, B. Hammounti and M. Bouachrine, Der Pharma Chemica., 2011, 3, 576-590.

54 W. J. Lorenz and F. Mansfeld, Corros. Sci., 1981, 21, 647-672.

55 J. Aljourani, K. Raeissi and M. A. Golozar, Corros. Sci., 2009, 51, 1836-1843.

56 K. F. Khaled and N. Hackerman, Mater. Chem. Phys., 2003, 82, 949-960.

57 M. A. J. Mazumder, M. K. Nazal, M. M. Faiz and S. A. Ali, RSC Adv., 2016, 6, 12348-12362.

58 R. M. El-Sherif and W. A. Badawy, Int. J. Electrochem. Sci., 2011, 6, 6469-6482.

59 C. Verma, P. Singh and M. A. Quraishi, J. Assoc. Arab Univ. Basic Appl. Sci., 2016, 21, 24-30.

60 T. Arsian, F. Kandemirli, E. E. Ebenso, L. Love and H. Alemu, Corros. Sci., 2009, 5, 35-47.

61 L. Larabi, Y. Harek, M. Traisnel and A. Mansri, J. Appl. Electrochem., 2014, 34, 833-839.

62 I. L. Rozenfeld, Corrosion Inhibitors, MacGraw-Hill, New York, 1981.

63 L. Afia, R. Salghi, L. Bammou, E. Bazzi, B. Hammouti, L. Bazzi and A. Bouyanzer, J. Saudi Chem. Soc., 2014, 18, 19-25.

64 G. W. Nelson, M. Perry, S. M. He, D. L. Zechel and J. H. Horton, Colloids Surf., B, 2010, 78, 61-68.

65 H. B. Yao, Y. Li and A. T. S. Wee, Appl. Surf. Sci., 2000, 158, 112-119.

66 N. Wu, L. Fu, M. Su, M. Aslam, K. C. Wong and V. P. Dravid, Nano Lett., 2004, 4, 383-386.

67 O. Olivares-Xometl, N. V. Likhanova, M. A. DomínguezAguilar, J. M. Hallen, L. S. Zamudio and E. Arce, Appl. Surf. Sci., 2006, 252, 2139-2152.

68 M. Tourabi, K. Nohair, M. Traisnel, C. Jama and F. Bentiss, Corros. Sci., 2013, 75, 123-133. 